Louisiana State University

LSU Digital Commons

Faculty Publications

Department of Biological Sciences

$1-1-2014$

\title{
Adaptive processes drive ecomorphological convergent evolution in antwrens (Thamnophilidae)
}

Gustavo A. Bravo

Louisiana State University

J. V. Remsen

Louisiana State University

Robb T. Brumfield

Louisiana State University

Follow this and additional works at: https://digitalcommons.Isu.edu/biosci_pubs

\section{Recommended Citation}

Bravo, G., Remsen, J., \& Brumfield, R. (2014). Adaptive processes drive ecomorphological convergent evolution in antwrens (Thamnophilidae). Evolution, 68 (10), 2757-2774. https://doi.org/10.1111/ evo.12506

This Article is brought to you for free and open access by the Department of Biological Sciences at LSU Digital Commons. It has been accepted for inclusion in Faculty Publications by an authorized administrator of LSU Digital Commons. For more information, please contact ir@lsu.edu. 


\title{
Adaptive processes drive ecomorphological convergent evolution in antwrens (Thamnophilidae)
}

\author{
Gustavo A. Bravo, ${ }^{1,2,3,4}$ J. V. Remsen Jr., ${ }^{1,2}$ and Robb T. Brumfield ${ }^{1,2}$ \\ ${ }^{1}$ Museum of Natural Science, Louisiana State University, Baton Rouge, Louisiana 70803 \\ 2Department of Biological Sciences, Louisiana State University, Baton Rouge, Louisiana 70803 \\ ${ }^{3}$ Current Address: Seção de Aves, Museu de Zoologia, Universidade de São Paulo (MZUSP), Caixa Postal 42.494, CEP \\ 04218-970, São Paulo, SP, Brasil \\ ${ }^{4}$ E-mail: gbravo1@usp.br
}

Received January 3, 2014

Accepted June 26, 2014

Phylogenetic niche conservatism (PNC) and convergence are contrasting evolutionary patterns that describe phenotypic similarity across independent lineages. Assessing whether and how adaptive processes give origin to these patterns represent a fundamental step toward understanding phenotypic evolution. Phylogenetic model-based approaches offer the opportunity not only to distinguish between PNC and convergence, but also to determine the extent that adaptive processes explain phenotypic similarity. The Myrmotherula complex in the Neotropical family Thamnophilidae is a polyphyletic group of sexually dimorphic small insectivorous forest birds that are relatively homogeneous in size and shape. Here, we integrate a comprehensive species-level molecular phylogeny of the Myrmotherula complex with morphometric and ecological data within a comparative framework to test whether phenotypic similarity is described by a pattern of PNC or convergence, and to identify evolutionary mechanisms underlying body size and shape evolution. We show that antwrens in the Myrmotherula complex represent distantly related clades that exhibit adaptive convergent evolution in body size and divergent evolution in body shape. Phenotypic similarity in the group is primarily driven by their tendency to converge toward smaller body sizes. Differences in body size and shape across lineages are associated to ecological and behavioral factors.

KEY WORDS: Adaptation, antwren, convergent evolution, ecological correlates, phenotypic disparity, Thamnophilidae.

Phenotypic similarity among independent lineages is a pervasive pattern observed across taxa (Conway Morris 2009; Losos 2011). When such similarity is observed across lineages that have a relatively recent common ancestor, it is often described as phylogenetic niche conservatism (PNC; Losos 2008; Wiens et al. 2010; Crisp and Cook 2012), but when distantly related species independently evolve to become more similar to each other, the pattern is attributed to convergent evolution (Stayton 2006; Losos 2011). Although the use of comparative methods facilitates the detection of both patterns, identifying the evolutionary mechanisms

This article was published online on 17 September 2014. Subsequently, it was determined that the $x$-axes of Figures 2 (panel B) and 4 (panel C) was mislabeled. The correction was published on 2 October 2014. responsible for them represents a major challenge (Losos 2008; 2011). For instance, PNC can result from fundamentally different processes, such as stabilizing selection, low genetic variation underlying the traits, gene flow among lineages, lack of opportunities for colonizing new niches, and genetic drift (Wiens and Graham 2005; Losos 2008; Crisp and Cook 2012). Similarly, convergent evolution can be the consequence of coincidence, adaptation via natural selection (e.g., Grant et al. 2004), exaptation (Gould and Vrba 1982), genetic drift (Stayton 2008), a correlated response to selection on another character (reviewed by Larson and Losos 2004; Losos 2011), or a community-wide response to competition (Scheffer and van Nes 2006). Therefore, distinguishing PNC from convergent evolution, as well as identifying the driving forces behind them represents a fundamental 
step toward understanding the mechanisms underlying phenotypic diversity.

With the exception of a few groups, such as lizards in the genus Anolis (e.g., Losos 1990; Harmon et al. 2005; Kolbe et al. 2011; Mahler et al. 2013), and fish in the families Cichlidae (e.g., Rüber and Adams 2001; Hulsey et al. 2008; Muschick et al. 2012) and Gasterosteidae (e.g., McGee and Wainwright 2013), the mechanistic underpinnings of phenotypic similarity in vertebrate groups is still poorly understood. Moreover, despite the rapidly increasing number of phylogenetic studies, suggesting the existence of either conserved or convergent phenotypic similarity, sufficient evidence to identify the mechanisms involved is difficult to amass (Losos 2008, 2011; Wiens et al. 2010).

Statistically based phylogenetic comparative methods can be used to quantify the degree of ecological and phenotypic similarity among related species while accounting for phylogenetic relatedness; this allows distinguishing ancestral from derived similarity and identifying potential routes to the latter (e.g., Stayton 2006; Revell et al. 2007a; Sidlauskas 2008). Phylogenetic comparative methods do not only represent a powerful quantitative tool to test whether such similarity is consistent with PNC or convergent evolution, but they also offer the possibility of revealing the potential role of natural selection and adaptation in driving phenotypic evolution among close relatives (Cooper et al. 2010).

The Myrmotherula complex (i.e., genus Myrmotherula sensu Zimmer and Isler 2003) in the Neotropical family Thamnophilidae is a polyphyletic group (Hackett and Rosenberg 1990; Irestedt et al. 2004; Brumfield et al. 2007; Belmonte-Lopes et al. 2012; Bravo et al. 2012a) that consists of 35 species of sexually dimorphic small insectivorous forest birds that are relatively homogeneous in size and shape. The complex is ideal for the study of evolutionary processes that underlie relationships between ecology and morphology because these birds form a tight ecological assemblage with high levels of intrageneric sympatry and syntopy (Stotz 1990). The complex has been traditionally subdivided into at least three groups defined by male plumage types, which also exhibit some behavioral and ecological differences, such as foraging behavior and habitat preferences (Fig. 1; Hackett and Rosenberg 1990; Stotz 1990; Ridgely and Tudor 1994; Zimmer and Isler 2003). The first group consists of 10 species, commonly referred to as the "streaked antwrens" that occur mainly in the canopy and forest borders of lowland forests; some species join mixed-species flocks in the canopy (e.g., Pearson 1977; Powell 1979; Munn 1985; Stotz 1990). The second group contains 13 species, commonly known as the "gray/slaty antwrens" that occur in the understory and midstory of lowland and subtropical forests; most species join understory mixed-species flocks (e.g., Munn and Terborgh 1979; Stotz 1990; Whitney 1994; Whitney and Pacheco 1997). The third group consists of eight species known as the "stipple-throated antwrens" based on their spotted throat plumage. These species are dead-leaf foraging specialists, and join understory mixed-species flocks (Hackett and Rosenberg 1990; Rosenberg 1990, 1993). They are now placed in the separate genus Epinecrophylla (Isler et al. 2006). Also, members currently placed in the genera Isleria and Rhopias show combinations of plumage, behavioral, and ecological characters that make their assignment into any of these ecomorphological groups difficult (Zimmer and Isler 2003). Some members of the genera Formicivora, Terenura, and Myrmochanes have been associated to the complex (e.g., Irestedt et al. 2004; Brumfield et al. 2007; Bravo et al. 2012b; Ohlson et al. 2013). The fivefold polyphyly in the complex (Hackett and Rosenberg 1990; Irestedt et al. 2004; Brumfield et al. 2007; Belmonte-Lopes et al. 2012; Bravo et al. 2012a) suggests different lineages within the complex have either converged into similar morphologies or have retained ancestral morphological features.

Here, we integrate a comprehensive species-level molecular phylogeny of the Myrmotherula complex with morphometric and ecological data within a comparative framework to test whether phenotypic similarity is due to PNC or to convergent evolution. Because body size and shape can be subject to different evolutionary processes (Miles and Ricklefs 1984), we take into account variation in body size and body shape separately to identify potential mechanisms for ecomorphological evolution in the complex. Also, we study ecological correlates of phenotypic diversification to assess their importance in explaining phenotypic similarity in the complex.

\section{Materials and Methods MOLECULAR DATA}

We sampled 126 vouchered thamnophilid individuals, including two samples from 33 of the 35 species currently and formerly recognized in Myrmotherula (Remsen et al. 2013 [13 September 2013]), and at least one individual from 30 other thamnophilid genera (Table S1). This taxon sampling not only represents all subfamilies and tribes within the family (sensu Moyle et al. 2009; Bravo et al. 2012b), but also spans the family's range of ecological and phenotypic variation. Samples of Myrmotherula sunensis and M. fluminensis were not available to us. One sample of Formicivora littoralis represents an unvouchered blood sample housed at Colecão de Ornitologia do Museu de Ciências e Tecnologia da Pontifícia Universidade Católica do Rio Grande do Sul (MCP; see Table S1 for acronym information). For outgroups, we included one representative of all other families in the infraorder Furnariides (Formicariidae, Rhinocryptidae, Grallariidae, Furnariidae, Conopophagidae, and Melanopareiidae; Moyle et al. 2009) and the family Pipridae in the infraorder Tyrannides (Tello et al. 2009).

We used standard methods described elsewhere (Groth and Barrowclough 1999; Barker et al. 2002; Brumfield and Edwards 
A
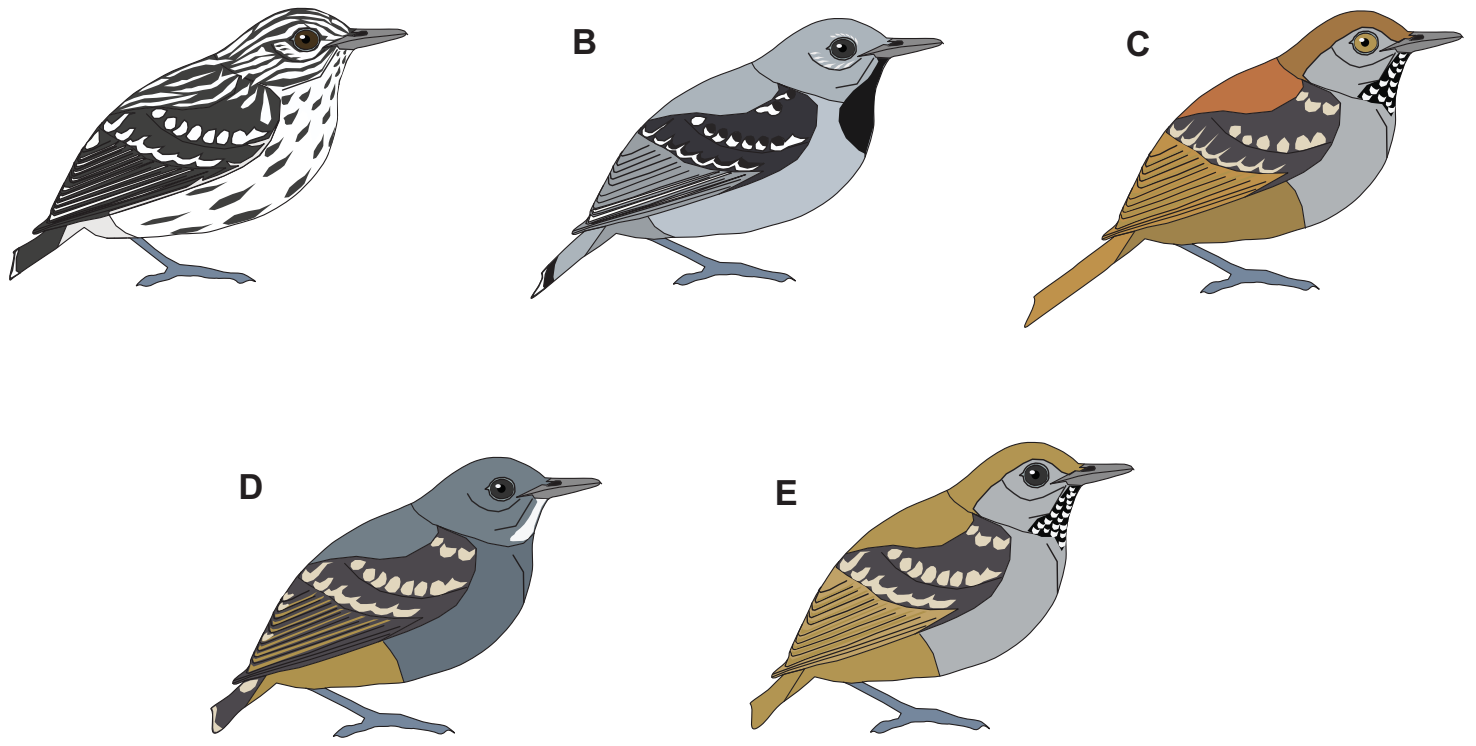

Figure 1. Plumage types traditionally recognized within the Myrmotherula complex. (A) Streaked assemblage (Myrmotherula surinamensis). (B) Gray assemblage (M. minor). (C) Stipple-throated assemblage (Epinecrophylla haematonota). (D) Isleria guttata. (E) Rhopias gularis.

2007; Brumfield et al. 2007) to extract total DNA from pectoral muscle and to amplify and obtain sequences for six genes. After combining newly obtained sequences with sequences from our previous work (Brumfield and Edwards 2007; Brumfield et al. 2007; Moyle et al. 2009; Gómez et al. 2010; Derryberry et al. 2011; Belmonte-Lopes et al. 2012; Bravo et al. 2012a,b), we were able to include sequences for all ingroup and outgroup individuals for three mitochondrial genes (cytochrome b - cytb, 1,045 bp; NADH dehydrogenase subunit 2-ND2, $1041 \mathrm{bp}$; and NADH dehydrogenase subunit 3-ND3, $351 \mathrm{bp}$ ) and one autosomal nuclear intron ( $\beta$-fibrinogen intron $5-\beta \mathrm{F} 5 ; 568 \mathrm{bp}$ ). For a subset of 57 individuals that represent genus-level clades, we included sequences of two protein-coding nuclear genes (recombination activation gene 1-RAG1, $2872 \mathrm{bp}$; recombination activation gene 2-RAG2, $1152 \mathrm{bp}$ ).

We edited sequences using Sequencher 4.7 (Gene Codes Corporation, Ann Arbor, MI) and checked that protein-coding sequences did not include stop codons or anomalous residues. We aligned sequences using the program MAFFT version 6 (Katoh et al. 2002), and obtained a concatenated dataset using Geneious Pro version 5.5 (Drummond et al. 2011). The final alignment included 7035 base pairs. Newly obtained sequences were deposited in GenBank (Accession numbers KM236249-KM236497).

\section{PARTITION AND SUBSTITUTION MODELS}

We estimated the optimal partitioning regime using the strategy described by $\mathrm{Li}$ et al. (2008) to designate partitions based on their similarity in evolutionary parameters. The data were fully partitioned (a different partition for each position of each cod- ing gene [15] and the nuclear intron) and each of the 16 data blocks was optimized independently under a GTR $+\Gamma$ model using the maximum-likelihood (ML) method in RAxML (Stamatakis 2006). We selected six partitioning strategies based on similarities of substitution rates, base composition, and the gamma parameter among data blocks (Table S2). We used RAxML to obtain likelihood values for each partition strategy under the GTR $+\Gamma$ model and identified the most informative strategy using the Akaike information criterion (AIC). We established that the most informative partition scheme included 16 partitions (the nuclear intron and each codon position for each coding gene are treated separately; Table S2). For each partition, we evaluated the 24 substitution models available from MrModeltest 2.3 (Nylander 2004) based on parameter estimation in PAUP* (Swofford 2003), and identified the best substitution model via comparison of AIC (Akaike 1974; Table S3).

\section{PHYLOGENETIC INFERENCE}

We generated a phylogenetic hypothesis for the Myrmotherula complex under both ML and Bayesian frameworks using the most informative partition scheme. ML analyses were conducted with the GTR $+\Gamma$ model of nucleotide substitution and 1000 bootstrap replicates using RAxML 7.2.7 (Stamatakis 2006) on the Cipres Science Gateway version 3.1 (Miller et al. 2010). Bayesian inference analyses in MrBayes 3.1.2 (Huelsenbeck and Ronquist 2001) were conducted on the University of Oslo Bioportal (Kumar et al. 2009). We performed the analysis with four runs and four MCMC chains, using 20 million generations with a sample frequency of 1000 , a chain temperature of 1.75 , and a 
burn-in of $20 \%$. The use of the "compare" and "slide" functions of AWTY online (Wilgenbusch et al. 2004) were used to assess the performance of Bayesian phylogenetic inference. The obtained Bayesian topology is available from the Dryad Digital Repository: http://doi.org/10.5061/dryad.21sf7.

We estimated a relative time-calibrated phylogeny in a Bayesian framework using the program BEAST version 1.6.1 (Drummond and Rambaut 2007). We used an uncorrelated lognormal model (UCLD; Drummond et al. 2006) with unlinked substitution models across partitions, and clock models linked by gene. Substitution parameters were based on results previously conducted in MrModeltest. Clock parameters used log-normal distributions with different means for each gene based on behavior of chains in preliminary runs. We used a Yule prior for tree shape with no restrictions on tree shape, and a randomly generated tree was used as a starting tree. Because subsequent analyses do not depend on estimation of absolute times but rather on relative times, no attempt to calibrate the tree based on absolute times was conducted. We ran analyses for a total of 200 million generations with a sampling frequency of 1000 . We determined that replicate analyses converged (effective sample size values $>400$ ) using Tracer version 1.5 (Drummond and Rambaut 2007). Using TreeAnnotator version 1.6.1 (Drummond and Rambaut 2007) and a burn-in of $20 \%$, we estimated a posterior distribution of topologies and the maximum clade credibility (MCC) tree. A simplified version of the relative time-calibrated phylogeny is available from the Dryad Digital Repository .

\section{MORPHOLOGICAL DATA}

From 362 museum specimens (4.3 individuals/species; Table S4), we obtained weight data from labels and measured 10 ecomorphological variables representing the size and shape of the bill, wing, tail, tarsus, and feet. Five species were represented by fewer than four measured specimens (Epinecrophylla fjeldsaai, $n=1$; Myrmotherula ambigua, $n=1 ;$ M. behni, $n=1$; Formicivora iheringi, $n=2$; and Euchrepomis spodioptila, $n=2$ ), and one species, Myrmotherula snowi, was completely excluded from morphological analyses due to the lack of available specimens. The ecomorphological nature of selected traits in birds (sensu Williams 1972) has been addressed in various studies both from a taxonomic (e.g., Pearson 1977; Schulenberg 1983; Fitzpatrick 1985) and a community perspective (e.g., Ricklefs and Travis 1980; Miles and Ricklefs 1984; Corbin 2008). Strong associations have been documented between behavior, ecology, and external morphology of these traits. Bill morphology has been shown to correlate with prey item and attacking behavior (e.g., Greenberg 1981; Schulenberg 1983; Fitzpatrick 1985); wing morphology affects attack methods and associates with foraging substrate (e.g., Schulenberg 1983; Fitzpatrick 1985); tail morphology is tightly associated with specific foraging movements, such as climbing (e.g., Norberg 1979; Claramunt et al. 2012), and affects maneuverability during foraging (Thomas and Balmford 1995); and morphology of feet and tarsi correlates with substrate utilization, searching movements, and perch types (e.g., Miles and Ricklefs 1984; Fitzpatrick 1985). For most species, we collected measurements from at least two adult males and two adult females. Measurements obtained were bill length, bill width, and depth at the level of the anterior border of the nostrils, wing length to the longest primary feather, wing length to the tenth primary feather, wing length to the first secondary feather, tail maximum length, central rectrix maximum width, tarsus length, and hallux length. All measurements were taken with a Mitutoyo Digimatic Point Caliper by GAB (for details see Baldwin et al. 1931; Claramunt 2010). Morphometric data were deposited as an associated document file in Microsoft Excel format in the Dryad Digital Repository: http://doi.org/10.5061/dryad.21sf7. Using a log-transformed dataset for all individuals, we obtained mean estimates of each morphological trait for every species. Using the phytools version 0.1-6 package (Revell 2012) in the R language for statistical computing (R Development Core Team 2011), we performed a phylogenetic size correction that uses the residuals from a least squares regression analysis, while controlling for nonindependence due to phylogenetic history (Revell 2009). We used log-transformed body weight as a proxy for body size. We then reduced the multivariate dataset to an uncorrelated set of variables using phylogenetic principal component analyses (Revell and Collar 2009; Revell 2012). All subsequent analyses were conducted based on this reduced dataset, except when noted.

\section{TESTING FOR PNC VERSUS CONVERGENT EVOLUTION}

To characterize and test PNC and convergent ecomorphological evolution of the Myrmotherula complex, we performed a suite of analyses (Wiens and Graham 2005; Losos 2008, 2011; Revell et al. 2008; Wiens et al. 2010). First, we assessed whether body size and shape variation in the complex differs significantly from that of the Thamnophilidae. Second, we tested for adaptive scenarios of body size and shape evolution and fitted models of continuous trait evolution (Harmon et al. 2003, 2008). Third, we explicitly assessed whether ecomorphological variation among lineages within the complex are consistent with a pattern of adaptive convergent evolution (Ingram and Mahler 2013; Mahler et al. 2013). Finally, we assessed whether certain ecological features are correlated with the evolution of specific ecomorphological traits. Details about these analyses are provided below.

\section{Body size and shape diversity}

To assess whether members of the Myrmotherula complex exhibit constrained ecomorphological diversity, we first quantified 
the size and shape components of ecomorphological variation within the family (i.e., all species included in the phylogenetic tree), and within all members in the Myrmotherula complex. A vector and a matrix describing size and shape variation, respectively, were estimated excluding body weight from the logtransformed averaged dataset following the approach described by Mosimann (1970) and Mosimann and James (1979). The size of each species is the mean of the 10 log-transformed ecomorphological variables of the species. The shape vector for each species is calculated by subtracting the size of the species from each variable (Mosimann 1970; Mosimann and James 1979). Because values of size and shape for any given taxon do not depend on inferences based on phylogenetic relatedness and values for other taxa, one of the fundamental advantages of this method is that size and shape quantification does not require accounting for phylogenetic independence (Claramunt 2010); quantification per se only depends on the observed variation among morphometric traits across taxa (Mosimann 1970; Mosimann and James 1979) regardless of phylogenetic relatedness. Further use in comparative analyses of the multispecies shape matrix (i.e., all of the species' shape vectors) and the size vector (i.e., all of the species' size values), does require explicit incorporation for phylogeny. On the other hand, other methods to estimate size and shape variation using regressions and principal components require accounting for phylogenetic relatedness because phylogenetic structure determines obtained size and shape values (reviewed by Revell 2009).

To estimate the relative contribution of body size and shape in both groups, we then estimated the shape/size variance ratio, based on computation of the total variance, a multivariate phenotypic diversity measurement that can be partitioned into size and shape components (Darroch and Mosimann 1985; Claramunt 2010). Because here we compare the volume occupied by size and shape variation of ecomorphological space regardless of phylogenetic relatedness, the size vector and the shape matrix do not have to be corrected for phylogeny. To assess whether the obtained shape/size variance ratio for the family and the Myrmotherula complex represented significant deviations from null expectations (i.e., Brownian motion), we compared the observed values against null distributions of expected ratios created by performing the same calculations on 999 permutations of the log-corrected morphological matrix with a significance threshold of 0.05 .

\section{Ecomorphological evolution over time}

To evaluate the rate of morphological evolution in relation to lineage diversification, we conducted disparity-through-time analyses (Harmon et al. 2003), as implemented in the Geiger package v.1.3 (Harmon et al. 2008) in R. We conducted these analyses for the size vector and for the size-corrected phylogenetic principal components of shape variation using the complete phylogeny, and using a trimmed phylogeny depicting only the history of the core Myrmotherula group (32 species; i.e., tribe Formicivorini [sensu Moyle et al. 2009]). Disparity-through-time analysis compares observed average phenotypic disparity among subclades relative to total disparity contained in the phylogeny with average phenotypic disparity simulated under Brownian motion. Then, it computes the morphological disparity index (MDI), which quantifies the overall difference in relative disparity compared with Brownian motion expectations, and describes whether disparity was accumulated during the early or recent history of the phylogeny. Negative MDI values indicate lower subclade disparity than expected under Brownian motion and generally describe clades that accumulated disparity during their early history (i.e., disparity distributed primarily among subclades). Positive MDI values represent clades that accumulated disparity during their recent history (i.e., disparity distributed primarily within subclades). We compared observed relative disparity with the mean expectation of 1000 simulations under Brownian motion.

To test whether mechanisms consistent with adaptive evolution have produced phenotypic divergence over time, we followed a model-based approach (Anderson 2008) that assessed which models of phenotypic evolution provides a better fit to the size and shape data given the phylogeny. For the size vector and for the size-corrected phylogenetic principal components of shape variation, we evaluated four models that have different implications for understanding the mechanisms generating phenotypic diversity: Brownian motion-BM (i.e., diffusive drift), Ornstein-Uhlenbeck-OU (i.e., bounded evolution around a single phenotypic optimum), early burst-EB (i.e., exponential variable rates), and white-noise-WN (i.e., moving optimum) models. Brownian motion represents diffusive drift with gradual phenotypic change at a constant rate (Felsenstein 1985) that can result from genetic drift or randomly fluctuating directional selection (Felsenstein 1988). OU is a modified Brownian motion model that describes phenotypic change with a tendency toward a central value (Hansen 1997; Butler and King 2004). OU is often associated either with a process of stabilizing selection in which variation of phenotypic traits revolves around stationary optimal values or adaptive peaks (Hansen 1997; Butler and King 2004), or with neutral evolution bounded within a small portion of phenotypic space (Harmon et al. 2010). EB describes a process in which evolutionary rates of phenotypic change increase or decrease exponentially through time (Harmon et al. 2010). We specifically assessed a scenario of exponentially decreasing rates of phenotypic evolution (rate parameter $<0$ ) that is analogous with a model of adaptive radiation: phenotypic change occurs rapidly after lineages enter available niches, and decreases as niches are filled (Simpson 1944). WN represents a process in which variation of phenotypic traits revolves constantly around moving optima, which generates evolutionary phenotypic change that is 
independent from phylogenetic relationships, and is sometimes associated to neutral evolution (Hunt 2006; Estes and Arnold 2007). Therefore, assessing these four models allows opportunities for finding patterns that are consistent with a role of adaptive processes in driving ecomorphological evolution.

\section{Testing for true convergent evolution}

To test whether ecomorphological similarities within the Myrmotherula complex might be the result of convergent evolution, we used the SURFACE package (Ingram and Mahler 2013) implemented in R. SURFACE allows one to explicitly model the macroevolutionary convergence of independent lineages in phenotypic space by fitting OU models that vary in the number of adaptive regimes allowed to evolve. The model selection procedure starts with a model in which there is only one adaptive regime in the phenotypic surface and then increases the number of peaks in a step-wise fashion. Then, to identify convergent adaptive peaks SURFACE tests whether corrected AIC (AICc) values improve as it allows to collapse compatible adaptive regimes found in different branches. Therefore, SURFACE assumes that all clades of the tree can be evolving around different optima (i.e., adaptive regimes) under an OU process, and allows the identification of those clades that are convergent. We ran SURFACE using a dataset containing the size vector for all species calculated following Mosimann (1970) and the two first phylogenetic principal components of size-corrected ecomorphological variation. To assess whether observed patterns of true convergence differ from those expected by Brownian motion, we compared the true convergence parameter $(\Delta k)$ from our observed data to those of 500 datasets simulated under a Brownian motion mode of evolution.

\section{Ecological correlates of phenotypic evolution}

We investigated the role of habitat, foraging strata, and flocking behavior in driving morphological evolution in the $M y r$ motherula complex. These ecological factors have been shown to correlate with behavioral and ecomorphological variation in birds (Miles and Ricklefs 1984; Fitzpatrick 1985; Winkler and Preleuthner 2001), including various antwrens and other species in the Thamnophilidae (Pearson 1977; Schulenberg 1983; Stotz 1990). To minimize potential effects of missing taxa in the phylogeny, we focused these analyses exclusively on the Formicivorini. Habitats and foraging strata were coded as categorical variables, based on previous descriptions (e.g., Pearson 1971; Wiley 1980; Stotz 1990; Whitney 1994; Stotz et al. 1996; Whitney and Pacheco 1997; Zimmer and Isler 2003) and recent updates based on our own field experience (Table S5). Habitats were coded into five categorical states, using the main habitat where each species is known to occur (tropical lowland evergreen forests, seasonally flooded evergreen/gallery forests, montane evergreen forests, tropical dry/white sand forests, open habitats). Foraging strata were coded into three categorical states that describe the height above ground in which each species primarily forages (understory, midstory, canopy). Quantitative estimates of mixedspecies flocking behavior (MSF) for 17 of the 33 species were obtained from the literature (Oniki 1971; Pearson 1977; Powell 1979; Gradwohl and Greenberg 1980; Munn 1985; Stotz 1990; Whitney and Pacheco 1997; Develey and Peres 2000; Develey and Stouffer 2001; Thiollay 2003) and then converted into three categorical states (no MSF 0-25\%, occasional-common MSF 25-75\%, obligate MSF 75-100\%; Table S5). For the remaining species, MSF was coded based on previous qualitative descriptions (Zimmer and Isler 2003) and our own field experience.

We first performed an ML estimation of ancestral character states for the three discrete ecological variables using the APE library (Paradis et al. 2004) in R. Following a modelbased approach, we evaluated a model of equal rates (ER), a model of symmetrical rates (SYM), and a model that allows all rates to be different (ARD). We tested whether habitat, foraging strata, and MSF groups are more different morphologically than would be expected from random differentiation given the phylogeny, by performing phylogenetic multivariate analyses of variance (MANOVAs) as implemented in the Geiger package in R. To assess evolutionary associations among ecological groups and specific ecomorphological features, we performed phylogenetic analyses of variance (ANOVAs) and post hoc tests for the size vector and each of the 10 size-corrected ecomorphological traits using phytools in $\mathrm{R}$ language.

\section{Results PHYLOGENY}

The phylogenetic analyses based on ML and Bayesian methods yielded identical, highly supported topologies (Fig. S1). This topology corroborates previous results that Myrmotherula is not monophyletic (Hackett and Rosenberg 1990; Isler et al. 2006; Belmonte-Lopes et al. 2012; Bravo et al. 2012a), with members of the genus placed in four distantly related clades (Myrmotherula sensu stricto, Epinecrophylla, Isleria, and Rhopias; Fig. 2). Myrmotherula sensu stricto itself is also paraphyletic with respect to the genera Terenura, Formicivora, Stymphalornis, and Myrmochanes. Taxonomic implications within Myrmotherula sensu stricto will be discussed and published elsewhere (Bravo et al., unpubl. ms.).

\section{BODY SIZE AND SHAPE DIVERSITY}

The distribution of the Myrmotherula complex in size-uncorrected morphological space was predominantly associated with 

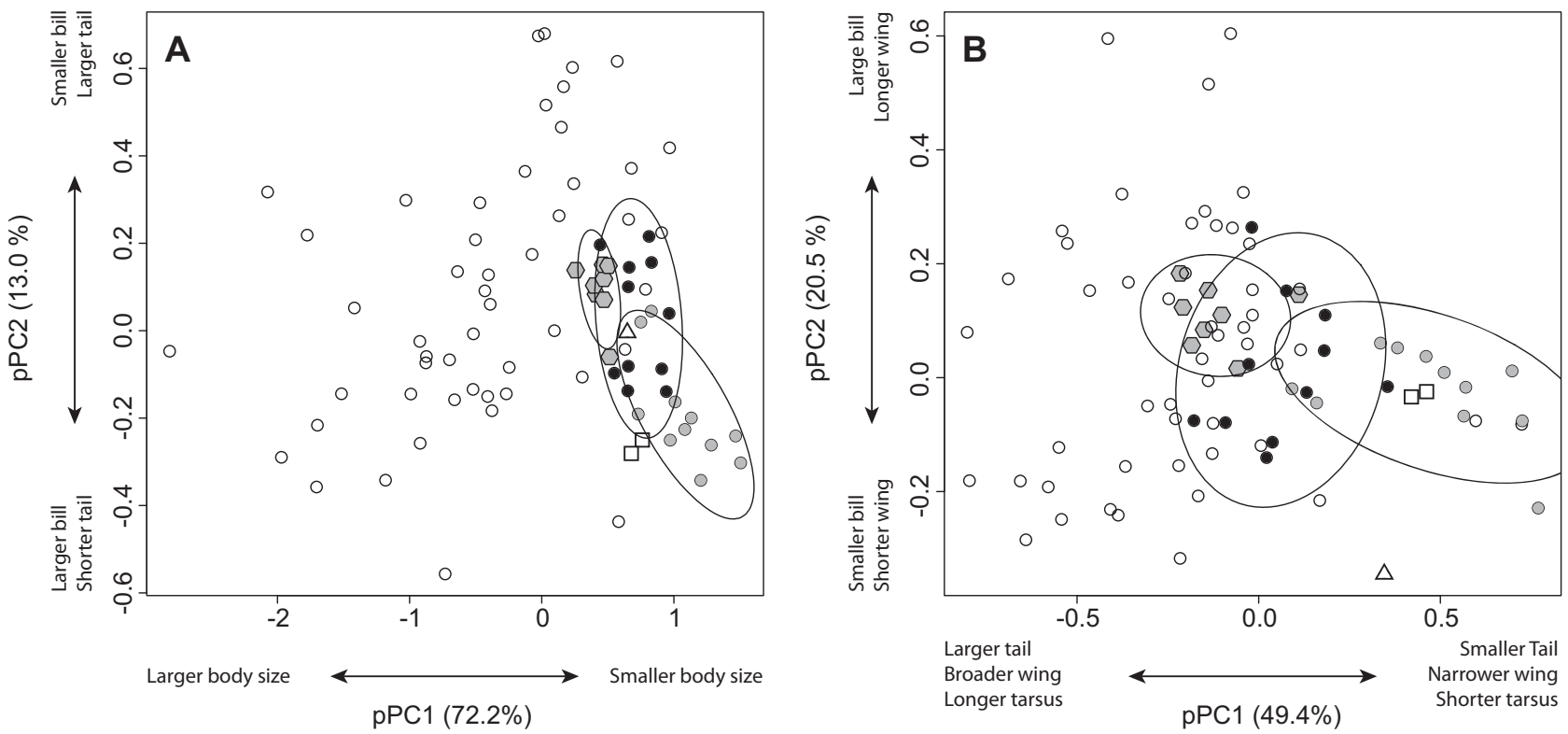

Figure 2. Size-uncorrected (A) and size-corrected (B) morphospace of the family Thamnophilidae showing that shape variation is greater than size variation among Myrmotherula complex plumage groups. Gray dots—streaked assemblage. Black dots-gray assemblage. Gray hexagons-stipple-throated assemblage. Hollow squares-Isleria guttata and I. hauxwelli. Hollow triangle-Rhopias gularis. Ellipses represent $95 \%$ confidence intervals.

Table 1. Factor loadings of ecomorphological variables in size-corrected and uncorrected phylogenetic principal component analyses.

\begin{tabular}{|c|c|c|c|c|c|c|c|c|}
\hline \multirow[b]{2}{*}{ Morphological Trait } & \multicolumn{4}{|c|}{ Size-Uncorrected Loadings } & \multicolumn{4}{|c|}{ Size-Corrected Loadings } \\
\hline & pPC1 & $\mathrm{pPC} 2$ & pPC3 & $\mathrm{pPC} 4$ & pPC1 & $\mathrm{pPC} 2$ & pPC3 & pPC4 \\
\hline $\begin{array}{l}\text { Wing length to longest } \\
\text { primary feather }\end{array}$ & -0.91 & -0.22 & -0.17 & 0.05 & -0.25 & 0.22 & -0.03 & -0.2 \\
\hline $\begin{array}{l}\text { Wing length to } 10 \text { th } \\
\text { primary feather }\end{array}$ & -0.86 & -0.33 & -0.2 & 0.03 & 0.06 & 0.27 & -0.1 & -0.13 \\
\hline $\begin{array}{l}\text { Wing length to first } \\
\text { secondary feather }\end{array}$ & -0.93 & -0.17 & -0.17 & 0.01 & -0.42 & 0.19 & -0.1 & -0.07 \\
\hline Tail maximum length & -0.82 & 0.51 & 0.19 & -0.15 & -0.96 & -0.01 & 0.21 & 0.14 \\
\hline $\begin{array}{l}\text { Central rectrix maximum } \\
\text { width }\end{array}$ & -0.9 & 0.3 & -0.07 & 0.27 & -0.88 & -0.09 & -0.27 & -0.36 \\
\hline Bill length & -0.77 & -0.42 & 0.13 & 0.19 & -0.04 & 0.7 & -0.32 & -0.21 \\
\hline Bill width & -0.69 & -0.48 & 0.46 & -0.01 & -0.05 & 0.94 & 0.02 & 0.02 \\
\hline Bill depth & -0.87 & -0.35 & 0.17 & -0.08 & -0.17 & 0.8 & 0.11 & 0.13 \\
\hline Tarsus length & -0.87 & -0.02 & -0.3 & -0.23 & -0.44 & -0.11 & -0.51 & 0.55 \\
\hline Hallux length & -0.84 & -0.17 & -0.36 & -0.2 & -0.2 & -0.03 & -0.69 & 0.55 \\
\hline
\end{tabular}

The distribution of the Myrmotherula complex in size-uncorrected morphological space was predominantly associated with variation in body size, whereas its distribution after size-correction was explained primarily by variation in tail length, rectrix width, tarsus, and wing breadth.

variation in body size $(\mathrm{pPC} 1=72.2 \%)$, whereas shape differences in tail and bill account for variation explained by pPC2 (13.0\%; Fig. 2A; see Table 1 for variable loadings). pPC1 showed a significant inverse correlation with log-transformed body weight $\left(F_{1,81}=941\right.$, adjusted $R^{2}=0.92, P<2.2 \times 10^{-16} ;$ Fig. S2). After ecomorphological space was size-corrected, the distribution was explained primarily by variation in tail length, rectrix width, tarsus, and wing breadth (pPC1 $=49.4 \%$; Fig. 2B; see Table 1 for variable loadings) and variation of bill dimensions was mainly associated with pPC2 (20.5\%). Differences in ecomorphospace between size-corrected and size-uncorrected datasets suggest greater variation in body shape than in size, relative to other members of the Thamnophilidae (Fig. 2). The shape/size variance ratio for all thamnophilids in the analysis was 0.24 , but the same 
ratio for members of the Myrmotherula complex was 1.25. A permutation analysis showed that the former ratio is much lower than expected by chance alone $(P<0.00001, \bar{x}=1.25, \mathrm{SE}=$ $0.001)$, and that the latter ratio is higher than expected by chance alone $(P<0.00001, \bar{x}=1.22, \mathrm{SE}=0.002)$.

\section{ECOMORPHOLOGICAL DIVERSIFICATION OVER TIME}

Body size disparity was primarily accumulated early in the history of the group among subclades (Fig. 3A; $\mathrm{MDI}_{\mathrm{SIZE}}=-0.19$ ), and the model that provided the best fit to the observed data was $\mathrm{EB}\left(\alpha=-0.06, \omega_{i}=0.97, \operatorname{lnL}=48.01, \mathrm{AIC}=-90.03\right.$, $\triangle \mathrm{AIC}$ of other models $>4$ ). When models of body size evolution were tested exclusively on the Formicivorini, body size disparity was also concentrated primarily among subclades (Fig. 3B; $\left.\mathrm{MDI}_{\text {SIZE }}=-0.10\right)$. OU $(\alpha=0.05, \operatorname{lnL}=33.45, \mathrm{AIC}=-60.90$, $\left.\omega_{i}=0.83\right)$, followed by BM $\left(\sigma^{2}=6.4 \times 10^{-4}, \operatorname{lnL}=30.56\right.$, $\left.\mathrm{AIC}=-57.12, \Delta \mathrm{AIC}=3.77, \omega_{i}=0.13\right)$ that provided the best fit for the observed pattern of body size evolution in the Formicivorini. Body shape disparity was also concentrated mainly among subclades both in the entire Myrmotherula complex and in the Formicivorini (Tables 2 and 3; Fig. 3B and 3D). However, a single model does not uniquely explain body shape evolution neither for the entire complex nor for the Formicivorini. All models were similarly informative to explain shape variation (Tables 2 and 3).

\section{CONVERGENT EVOLUTION}

SURFACE analyses support a scenario in which both body size and shape evolve around adaptive peaks at the family level. Sixteen shifts of regime were identified to occur. The most informative model included 10 independent adaptive regimes $\left(k^{\prime}\right)$, three of which appear after multiple shifts in independent branches $\left(k_{\text {conv }}^{\prime}\right)$ and are thus considered to exhibit true convergence $\left(\log \operatorname{lik}_{\text {size }}\right.$ $=94.75, \log \operatorname{lik}_{\mathrm{pPC} 1}=39.37, \log \operatorname{lik}_{\mathrm{pPC} 2}=66.04, \alpha_{\text {size }}=3.62$ $\times 10^{-3}, \alpha_{\mathrm{pPC} 1}=6.02 \times 10^{-2}, \alpha_{\mathrm{pPC} 2}=1.2 \times 10^{-1}, \sigma_{\text {size }}^{2}=$ $3.42 \times 10^{-4}, \sigma_{\mathrm{pPC} 1}^{2}=3.29 \times 10^{-3}, \sigma_{\mathrm{pPC} 2}^{2}=3.09 \times 10^{-3}$, $\left.\mathrm{AICc}=-268.19, \omega_{i}=0.91\right)$. Information on other informative models can be found in Table 4 . The three regimes exhibiting true convergence include all members of the Myrmotherula complex, as well as the genera Formicivora, Terenura, Stymphalornis, Myrmochanes, Drymophila, and Herpsilochmus (Fig. 4A). Inferred adaptive peaks of body size for the three convergent regimes are below observed values for all species, which suggests that, contrary to other members of the family, lineages in these clades are evolving toward smaller body sizes (Fig. 4B). These three regimes seem to be evolving toward diverging adaptive peaks in body shape, which suggest that members of the complex are drifting apart in tail, wing, and tarsus morphology (Fig. 4C). Although the fitted OU model might not reflect the biological reality in terms of the magnitude of optimal phenotypes, especially for body size, it captures the tendency of different adaptive regimes to evolve in different directions. Observed true convergence, measured as the reduced number of regimes after accounting for convergence $(\Delta k=6)$, is significantly higher than the mean value resulting from the distribution of $\Delta k$ from 500 datasets simulated under Brownian motion $(t=-34.34, P<0.00001, \bar{x}=3.54, \mathrm{SE}=$ 0.07). However, its value coincides with the $95 \%$ percentile of the distribution of $\Delta k$ from the 500 simulated datasets (Fig. 4D). In other words, the degree of observed convergence was lower than random convergence approximately $5 \%$ of the times, but was significantly higher than the mean convergence level across Brownian motion simulated datasets.

\section{ECOLOGICAL CORRELATES OF PHENOTYPIC EVOLUTION}

Reconstruction of ancestral character states of habitat and foraging strata was most informative under a model of ERs, whereas a symmetrical model was most informative for MSF behavior (Fig. S3; Table S6). The ML ancestral state for habitat was tropical lowland evergreen forest (scaled likelihood $=94.1 \%$ ), for foraging strata was understory (scaled likelihood $=79.3 \%$ ), and for MSF behavior was occasional-common (scaled likelihood = $64.2 \%)$.

Results from phylogenetic MANOVAs on the phylogenetic size-corrected principal components of the ecomorphological variation showed associations between morphological characters and habitat (Fig. 5; $F_{4,27}=3.79$, Wilks' $\lambda=0.25, P<0.001$ ), forest strata $\left(F_{2,29}=7.14\right.$, Wilks' $\left.\lambda=0.31, P<0.0001\right)$, and MSF behavior $\left(F_{2,29}=14.34\right.$, Wilks' $\left.\lambda=0.15, P<0.0001\right)$. Ecological variables predicted variation in body size. Species of open habitats were significantly larger than those of tropical lowland evergreen forests and seasonally flooded forests (Fig. 5; $F=7.07$, $P=0.012$ ). Likewise, species of tropical dry/white sand forests were significantly larger than those of seasonally flooded forests. Also, two body size groups were recovered based on foraging strata (Fig. 5; $F=15.08, P=0.02$ ): larger species forage in the understory, whereas species of the canopy are smaller. Midstory birds do not differ significantly from either canopy or understory birds. Species that do not join mixed-species flocks are significantly larger than those that are obligate mixed-flock members and those that join them occasionally $(F=26.98, P=0.002)$. Regarding shape variation, species of open habitats and tropical dry/white sand forests have longer $(F=6.26, P=0.010)$ and wider tails $(F=6.98, P=0.007)$, longer tarsi $(F=8.85, P=$ $0.003)$, and longer halluces $(F=8.59, P=0.003)$. Likewise, species that do not join mixed-species flocks have longer $(F=$ 13.62, $P=0.02)$ and wider tails $(F=13.31, P=0.03)$, longer tarsi $(F=82.02, P=0.001)$, and longer halluces $(F=21.92$, 


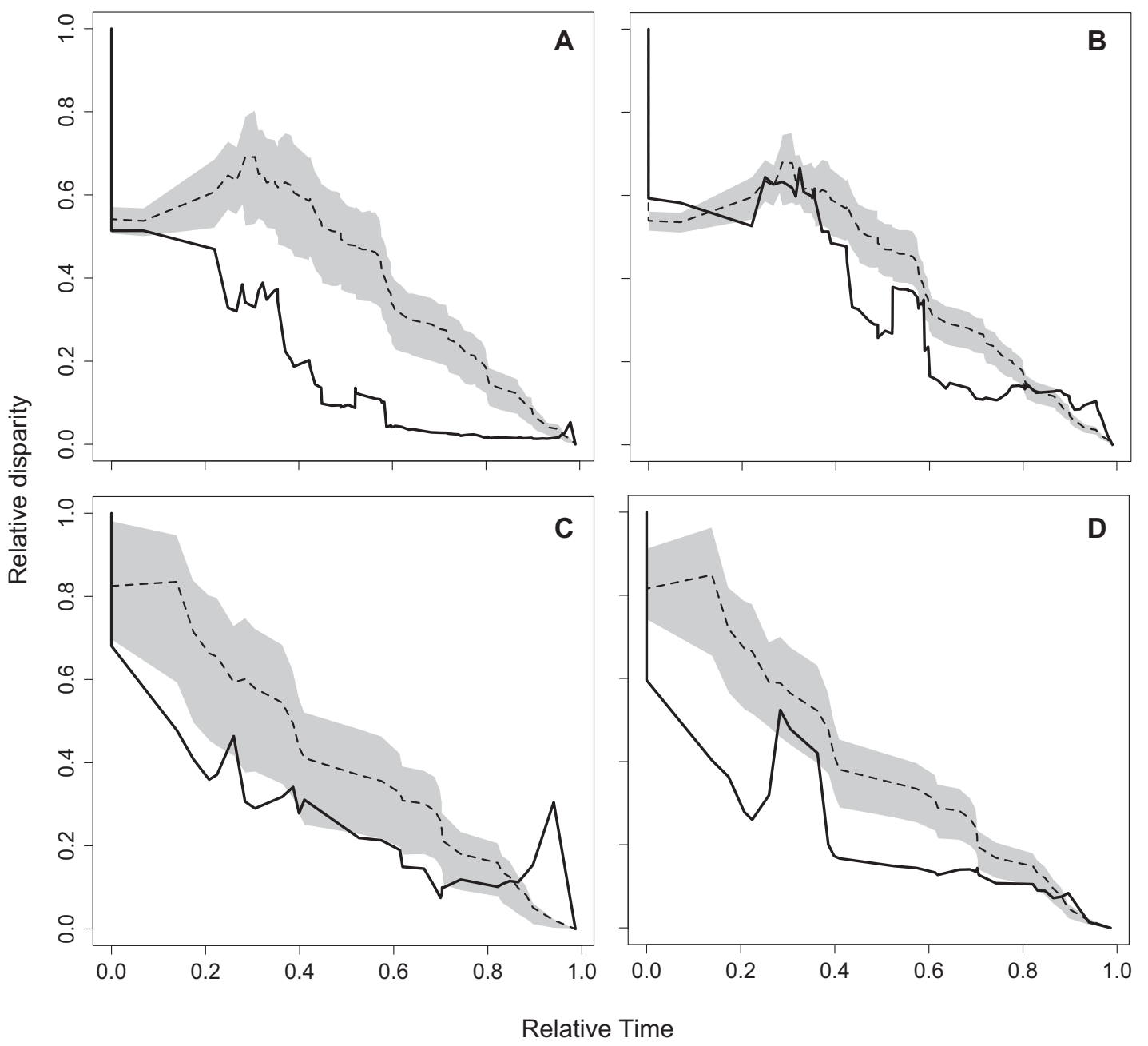

Figure 3. Disparity-through-time plots for size (A and C) and shape (B and D) for the complete Myrmotherula complex (top) and the Formicivorini (bottom). Relative to expectations under Brownian motion, size disparity was accumulated at a slower pace than shape disparity. Solid line represents observed disparity. Dashed line represents the mean of 999 Brownian motion simulations and gray area denotes distribution of simulations between 25 and $75 \%$ quartiles.

$P=0.01)$. Species that forage in the canopy have relatively shorter wings $(F=19.26, P=0.008)$ and shorter secondary feathers $(F=18.79, P=0.01)$ than do those species that forage in other forest strata.

\section{Discussion}

\section{ECOMORPHOLOGICAL CONVERGENT EVOLUTION IN} THE MYRMOTHERULA COMPLEX

The Myrmotherula complex consists of different distantly related clades that underwent ecomorphological convergent evolution. Relative to the ecomorphological variation observed in the Thamnophilidae, these clades are similar in body size, but different in body shape. Within clades, the evolution of body shape and size is bounded around phenotypic optima (i.e., PNC) that are associated with habitat and microhabitat components. Phenotypic optima observed for different clades tend toward lower values of body size, but diverge in tail, tarsus, and wing shape. This is consistent with the idea that stabilizing selection within each clade might be responsible for generating divergent morphotypes among clades, but relatively cohesive morphotypes within clades. Also, it suggests that high levels of syntopy among members of different clades (e.g., Amazonia) are possible, despite their similar size, because they are excluding each other ecologically by using different resources (e.g., prey items, microhabitat). Therefore, this diverse complex of insectivorous birds has likely undergone adaptive processes similar to other ecologically diverse and species-rich groups (e.g., MacArthur and Levins 1967). 

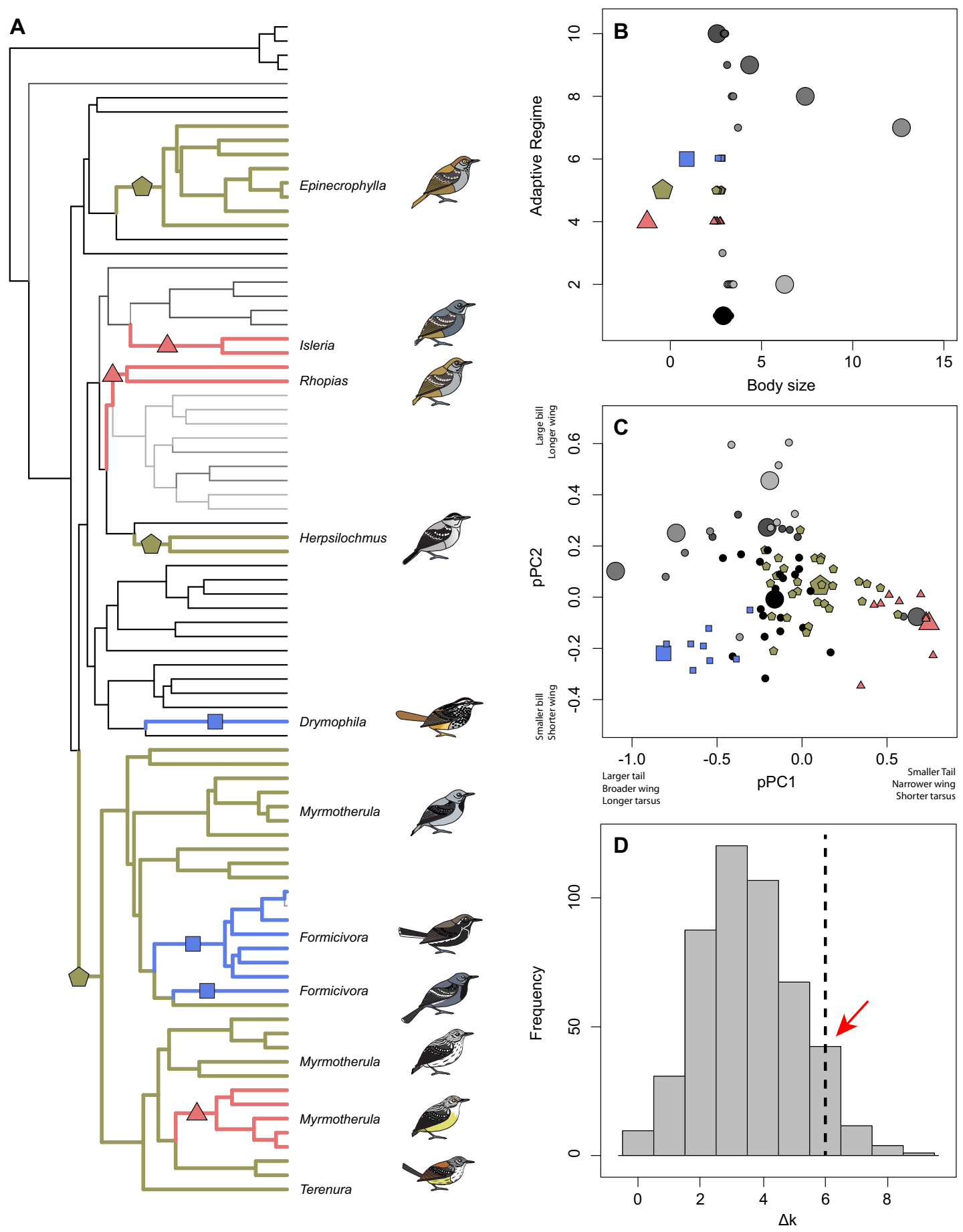

Figure 4. Convergent adaptive regimes of the Myrmotherula antwrens. (A) Relative time-measured phylogeny of the Thamnophilidae with adaptive regimes identified by SURFACE. Colored branches represent convergent adaptive regimes and gray or black branches denote nonconvergent regimes. Symbols on branches label the three convergent adaptive regimes that involve all members of the Myrmotherula complex and other morphologically similar antwrens (adaptive regime 4: red triangle; 5: green pentagon; 6: blue square). (B) Representation of how extant members of adaptive regimes (small symbols) tend toward adaptive optima of body size (large symbols). Convergent regimes tend toward small values of body size, whereas nonconvergent regimes tend toward larger body sizes (adaptive regime 4: red triangles; 5: green pentagons; 6: blue squares). (C) Size-corrected morphospace of the family Thamnophilidae showing that adaptive optima involving members of the Myrmotherula complex and other antwrens tend to diverge in tail, wing, and tarsus morphology. (D) Frequency distribution of levels of true convergence $(\Delta k)$ resulting from 500 Brownian motion simulations. The observed pattern of convergence is greater than average expectations by chance alone. The black dashed line represents the $95 \%$ quantile and the red arrow represents the observed value of true convergence. 
Table 2. Information theoretic statistics and ranking for each of the five models of character evolution evaluated for the five principal components of body shape for the entire phylogeny.

\begin{tabular}{lllccc}
\hline Shape Trait & Model & Rank & lnL & $\Delta$ AIC & $\omega_{i}$ \\
\hline pPC1 (MDI $=-0.09)$ & BM $\left(\sigma^{2}=3.3 \times 10^{-3}\right)$ & 1 & -0.82 & 0 & 0.55 \\
& EB $(r=-0.02)$ & 2 & -0.60 & 1.55 & 0.25 \\
& OU $\left(\alpha=1.4 \times 10^{-13}\right)$ & 3 & -0.82 & 2.00 & 0.20 \\
pPC2 (MDI =0.06) & WN $\left(\sigma^{2}=0.13\right)$ & 4 & -31.96 & 62.28 & 0 \\
& OU $(\alpha=0.02)$ & 1 & 37.02 & 0 & 0.50 \\
& BM $\left(\sigma^{2}=1.3 \times 10^{-3}\right)$ & 2 & 35.68 & 0.67 & 0.36 \\
& EB $\left(r=-1.3 \times 10^{-10}\right)$ & 3 & 36.68 & 2.67 & 0.13 \\
pPC3 (MDI $=-0.02)$ & WN $\left(\sigma^{2}=0.04\right)$ & 4 & 20.90 & 30.24 & 0 \\
& OU $\left(\alpha=7.9 \times 10^{-17}\right)$ & 1 & 75.76 & 0 & 0.53 \\
& BM $\left(\sigma^{2}=5.3 \times 10^{-4}\right)$ & 2 & 74.33 & 0.86 & 0.34 \\
& EB $\left(r=-3.0 \times 10^{-13}\right)$ & 3 & 74.33 & 2.86 & 0.13 \\
pPC4 (MDI $=0.05)$ & WN $\left(\sigma^{2}=0.01\right)$ & 4 & 59.27 & 31.00 & 0 \\
& OU $(\alpha=0.03)$ & 1 & 81.91 & 0 & 0.92 \\
& BM $\left(\sigma^{2}=4.9 \times 10^{-4}\right)$ & 2 & 78.09 & 5.64 & 0.06 \\
& EB $\left(r=-8.6 \times 10^{-12}\right)$ & 3 & 78.09 & 7.64 & 0.02 \\
\hline WN $\left(\sigma^{2}=0.01\right)$ & 4 & 72.81 & 16.20 & 0 \\
\hline
\end{tabular}

BM, Brownian motion; OU, Ornstein-Uhlenbeck; EB, early burst; WN, white noise. Statistics provided are $\triangle$ AIC value, and Akaike weight $\left(\omega_{i}\right)$. Morphological disparity index (MDI) is also provided for each component.

Table 3. Information theoretic statistics and ranking for each of the five models of character evolution evaluated for the three principal components of body shape in the formicivorini.

\begin{tabular}{|c|c|c|c|c|c|}
\hline Shape Trait & Model & Rank & $\ln L$ & $\Delta \mathrm{AIC}$ & $\omega_{i}$ \\
\hline \multirow[t]{4}{*}{$\mathrm{pPC} 1(\mathrm{MDI}=-0.20)$} & $\mathrm{BM}\left(\sigma^{2}=3.6 \times 10^{-3}\right)$ & 1 & 2.80 & 0 & 0.44 \\
\hline & $\mathrm{EB}(r=-0.06)$ & 2 & 3.68 & 0.26 & 0.39 \\
\hline & $\mathrm{OU}\left(\alpha=1.9 \times 10^{-12}\right)$ & 3 & 2.80 & 2.00 & 0.16 \\
\hline & $\mathrm{WN}\left(\sigma^{2}=0.19\right)$ & 4 & -18.75 & 43.11 & 0.0 \\
\hline \multirow[t]{4}{*}{$\mathrm{pPC} 2(\mathrm{MDI}=0.23)$} & $\mathrm{WN}\left(\sigma^{2}=0.01\right)$ & 1 & 25.14 & 0 & 0.57 \\
\hline & $\mathrm{OU}(\alpha=0.58)$ & 2 & 25.85 & 0.57 & 0.43 \\
\hline & $\mathrm{BM}\left(\sigma^{2}=1.3 \times 10^{-3}\right)$ & 3 & 18.85 & 12.58 & 0.00 \\
\hline & $\mathrm{EB}\left(r=-1.4 \times 10^{-10}\right)$ & 4 & 18.85 & 14.58 & 0.00 \\
\hline \multirow[t]{4}{*}{ pPC3 (MDI $=-0.08)$} & $\mathrm{BM}\left(\sigma^{2}=5.6 \times 10^{-4}\right)$ & 1 & 32.62 & 0 & 0.46 \\
\hline & $\mathrm{OU}\left(\alpha=2.3 \times 10^{-17}\right)$ & 2 & 33.37 & 0.49 & 0.36 \\
\hline & $\mathrm{EB}\left(r=-9.7 \times 10^{-12}\right)$ & 3 & 32.62 & 2.00 & 0.17 \\
\hline & $\mathrm{WN}\left(\sigma^{2}=0.01\right)$ & 4 & 22.12 & 21.00 & 0.00 \\
\hline
\end{tabular}

BM, Brownian motion; OU, Ornstein-Uhlenbeck; EB, early burst; WN, white noise. Statistics provided are $\Delta$ AIC value, and Akaike weight $\left(\omega_{i}\right)$. Morphological disparity index (MDI) is also provided for each component.

\section{EVOLUTION OF BODY SIZE VERSUS EVOLUTION OF BODY SHAPE IN THE MYRMOTHERULA COMPLEX}

The relative contribution of body size variation in the Myrmotherula complex is considerably lower than that of shape variation (Fig. 2). That the shape/size variation ratio is greater within the Myrmotherula complex than across a larger sample of species encompassing the entire ecomorphospace occupied by the family Thamnophilidae suggests either that phenotypic similarities among the disparate Myrmotherula clades reflect evolutionary constraints on body size, but not shape, or that body size variation is greater than body shape variation when quantified for all Thamnophilidae (Claramunt 2010). Despite methodological differences between our calculations for the Myrmotherula complex and those for the entire family (Claramunt 2010), these contrasting but complementary patterns likely reflect scale-dependent processes that operate differentially across stages of the diversification process. The pattern described for the entire family results in greater variance in body size because it represents the outcome of several evolutionary processes acting on more lineages at various phylogenetic, spatial, and temporal scales, whereas the pattern 
Table 4. Information theoretic statistics and ranking for each of the "backward" phase SURFACE models evaluating the number of shifts and adaptive regimes in the thamnophilidae.

\begin{tabular}{lllllll}
\hline Rank & $k^{\prime}$ & $\Delta k$ & $k_{\text {conv }}^{\prime}$ & AICc & $\Delta$ AICc & $\omega_{i}$ \\
\hline 1 & 10 & 6 & 3 & -268.19 & 0 & 0.91 \\
2 & 12 & 4 & 3 & -263.52 & 4.67 & 0.09 \\
3 & 13 & 3 & 2 & -255.79 & 12.40 & 0 \\
4 & 16 & 0 & 0 & -227.74 & 40.45 & 0 \\
\hline
\end{tabular}

Statistics provided are number of distinct regimes $\left(k^{\prime}\right)$, reduced number of regimes after accounting for convergence $(\Delta k)$, number of convergent regimes reached by multiple shifts ( $k_{\text {conv }}^{\prime}$ ), corrected AIC (AICc), $\triangle \mathrm{AICc}$ value, and Akaike weight $\left(\omega_{i}\right)$.

described for the Myrmotherula complex reflects the outcome of evolutionary processes acting on more constrained scales and on a relatively similar group ecologically and behaviorally.

\section{EVOLUTION OF BODY SIZE IN THE MYRMOTHERULA COMPLEX}

Body size evolution in the Myrmotherula complex is inconsistent with a heterogeneous Brownian motion process (i.e., diffusive drift), and has not evolved under a constant rate over time. Observed patterns of body size evolution are consistent with a time-dependent model of fluctuating selection of decreased fluctuation rates among adaptive peaks over time (Revell et al. 2008). In other words, body size evolution in the Myrmotherula complex fits a model in which a highly variable environment in space and time offers multiple adaptive peaks that cause fluctuations in the intensity and directionality of selection over time, ultimately leading to changes in body size (Estes and Arnold 2007; Labra et al. 2009; Bell 2010; Uyeda et al. 2011) and phenotypic convergence among distantly related groups. Under this scenario, higher rates of accumulation of body size disparity followed by a decrease in the rate of size evolution are consistent with a decrease in the rate of change among adaptive peaks (i.e., ecological opportunities hypothesis; Ricklefs 2006; Harmon et al. 2010; Mahler et al. 2010) that results in bounded evolution around optimal values (Simpson 1944).

Whether the observed adaptive pattern leading to convergence is the result of selective processes acting directly on body size remains to be explored further. Convergence is not necessarily the result of adaption (Revell et al. 2007b). As reviewed by Losos (2011), it can be the result of coincidence, adaptation, exaptation, or a correlated response to selection on another character. In some terrestrial vertebrate groups, it has been suggested that convergent evolution is primarily observed in body shape as a result of adaptation in allopatry mediated by ecological factors such as energetics, locomotion, perch location and structure, and food item size (e.g., Grant et al. 2004; Harmon et al. 2005; Wiens et al. 2006). However, if body size strongly influences resource use, strong stabilizing selection around optimal values of size might have resulted in all coexisting and potentially competing members of the Myrmotherula complex to have a similar size (i.e., phenotypic clustering; Gómez et al. 2010), but to differ in other phenotypic traits. This has been proposed as a potential mechanism to explain phenotypic similarity in species-rich communities (Scheffer and van Ness 2006), and it has been described in a group of broadly sympatric North American salamanders (Kozak et al. 2009), cichlid fishes in Africa (Muschik et al. 2012), aquatic beetles, and prairie birds (reviewed by Scheffer and van Ness 2006). If distantly related groups of the complex originated in allopatry and selection acts directly on body size, convergent evolution in body size would be the result of adaptation (e.g., Harmon et al. 2005; Aliabadian et al. 2012; McGee and Wainwright 2013). In contrast, if those clades originated in the same geographic areas exhibiting similar high levels of sympatry and syntopy as they do today, then it would be likely that body size is not the main subject of natural selection and that convergence would be the result of exaptation or correlated response to selection on other phenotypic traits (e.g., Poe et al. 2007).

\section{ECOLOGICAL CORRELATES OF BODY SIZE EVOLUTION IN THE MYRMOTHERULA COMPLEX}

Associations among some ecomorphological and ecological traits of the Formicivorini provide further evidence that body size evolution revolves around adaptive peaks. Although our analyses lack power to detect causation between ecological attributes and variation of body size or to pinpoint specific ecological attributes triggering variations in body size, they showed that larger species are associated with tropical dry forests and open habitats, and with lower foraging strata. Reconstruction of ancestral states showed that habitat and foraging strata diverged among clades early in history, supporting the idea that changes in body size coincided with changes in habitat and foraging strata. In reality, a combination of various ecological and environmental factors not directly assessed in our analyses is likely to influence these evolutionary associations between body size and habitat attributes. Differential effects of these factors along with stochastic processes would partially explain the observed variation in body size among species in those adaptive regimes converging toward smaller body sizes. For instance, higher seasonality (e.g., Murphy 1985) and aridity (e.g., Hamilton 1958) might favor increased body size, and higher humidity favors smaller body size (e.g., Hamilton 1958). Differences in vegetation density and microhabitat structure might provide an explanation for differences correlated with foraging strata. A correlation between vertical vegetation density and the intensity of foraging activity causes smaller species to forage in denser vegetation located in higher strata, whereas larger species make use of less dense vegetation of lower strata (e.g., Pearson 1971; 

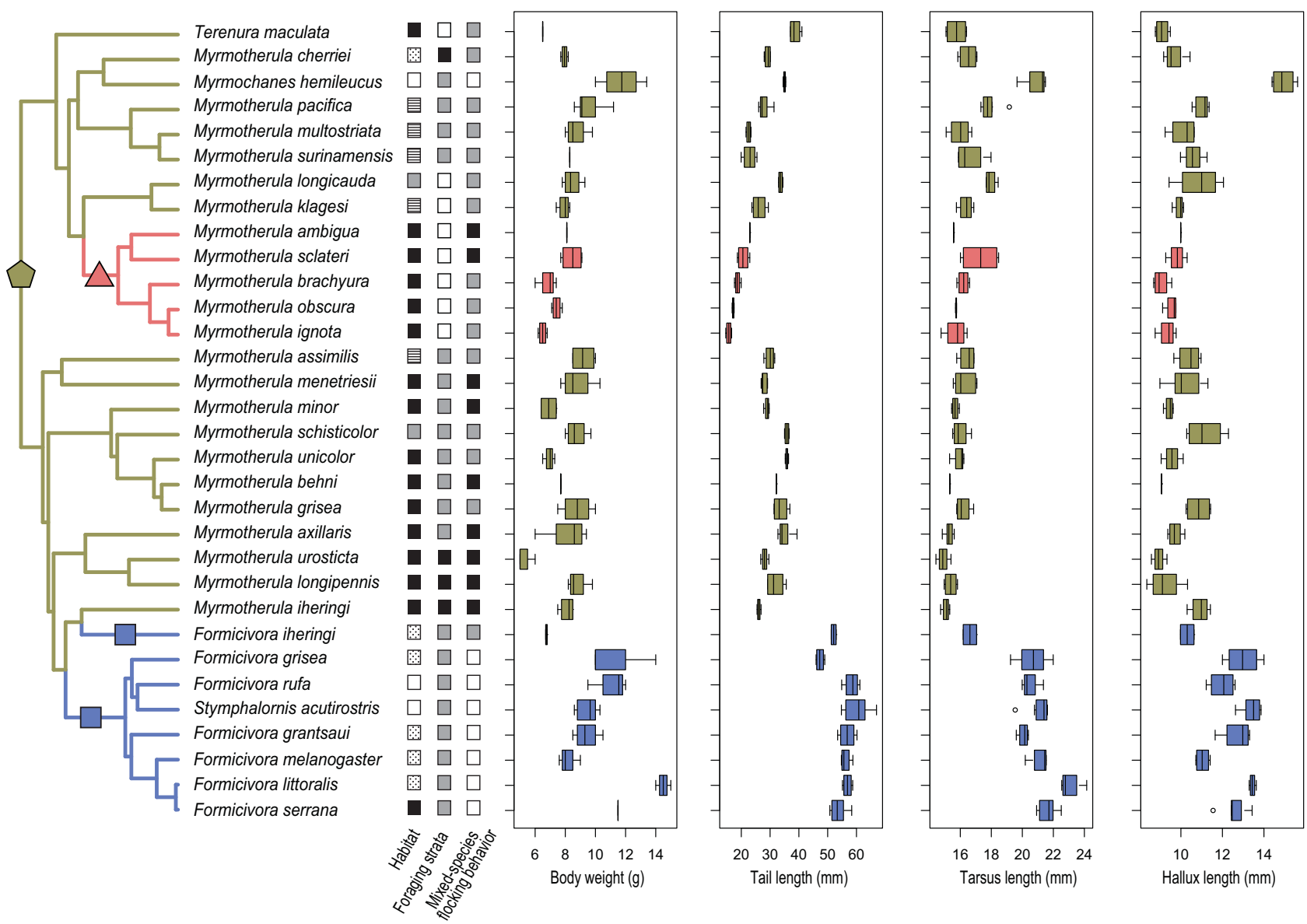

Figure 5. Mapping of ecological and morphological character states onto the relative time-measured phylogeny of the Formicivorini. Colors and symbols on branches denote the three convergent adaptive regimes identified in the tribe (adaptive regime 4: red triangles; 5: green pentagons; 6: blue squares). (1) Habitat: tropical lowland evergreen forest (black), seasonally flooded forest/gallery forest (horizontal lines), montane evergreen forest (gray), tropical dry/white sand forest (dots), open habitats (white). (2) Foraging strata: understory (black), midstory (gray), canopy (white). (3) MSF behavior: no MSF (white), occasional MSF (gray), obligate MSF (black).

Greenberg 1979; Stotz 1990). Physical constraints conferred by larger size impede the movement in restricted spaces and the use of smaller branches (Greenberg 1979). However, other potential correlates, such as productivity, microhabitat structure, and interspecific competition might also provide mechanistic explanations of these associations (e.g., Pearson 1977; Stotz 1990; Greve et al. 2008; Olson et al. 2009) and should be further explored, especially in tropical birds.

\section{EVOLUTION OF BODY SHAPE IN THE MYRMOTHERULA COMPLEX}

Shape evolution is not responding solely to any single mechanism, but represents a mosaic of different adaptive and nonadaptive processes acting differently on various components of ecomorphospace. Because the intensity of selective pressures differs across ecomorphospace (e.g., Losos 1990; Kozak et al. 2005), and some traits are known to evolve as a consequence of selec- tive pressures on other traits (e.g., Grant and Grant 2002; Irschick et al. 2008), such a noisy pattern was expected. Differences in tail, tarsus, and the first secondary feather were accumulated earlier in history, whereas differences in other traits were concentrated in the recent history of the group.

In the Formicivorini, high rates of disparity accumulation early in history, high phylogenetic signal with phenotypic change concentrated toward the base of the tree, make the evolution of tail and tarsus consistent with a process of adaptive radiation. Moreover, simulations of two time-dependent models (genetic drift and decreased fluctuation rates among adaptive peaks Revell et al. 2008) are in accordance with the information obtained for the evolution of tail and tarsus. Bill evolution was best explained by models in which character evolution revolves around near constant well-differentiated adaptive peaks that carry low phylogenetic signal, suggesting that bill shape might be highly tied to specific ecological conditions and that the amount of change 
in bill shape is almost equally distributed throughout the clade (i.e., functional constraints; Revell et al. 2008). This represents an expected pattern because bill morphology in passerine birds has been regarded as highly labile with low phylogenetic signal (Remsen 2003). Wing and hallux evolution is consistent with true Brownian motion evolution or constant stabilizing selection with weak selective pressures (Revell et al. 2008).

\section{ECOLOGICAL CORRELATES OF BODY SHAPE EVOLUTION IN THE MYRMOTHERULA COMPLEX}

Evolution of shape in the Myrmotherula complex can be partially explained by habitat, foraging strata, and mixed-flocking behavior associations. Differentiation of habitat and foraging strata occurred early in history in concert with changes in the principal components of ecomorphological variation, and a statistical association was found between tail, tarsus, and hallux and specific ecological traits. Such ecological associations have been shown not only to drive phenotypic diversification, but also to explain convergent patterns of morphological evolution in other groups (Losos 1990; Blackledge and Gillespie 2004; Aliabadian et al. 2012; Edwards et al. 2012; Lindgren et al. 2012; Muschick et al. 2012; Nyakatura 2012; Schelumpberger and Renner 2012). Previous work based on quantitative characterization of ecology and foraging behavior found that associations between tail, feet, and tarsal morphology can be explained by mechanical and physiological adaptations in specific conditions (e.g., Pearson 1977; Fitzpatrick 1985; Stotz 1990; Price 1991; Rosenberg 1993). If such constraints on performance ultimately affect individuals' fitness, then these associations likely have evolved as a consequence of varying selective pressures toward specific adaptive peaks combined with other processes such as drift.

Here, we have shown that examination of size and shape evolution in the Myrmotherula complex is consistent with adaptive processes. Body size in the group represents a convergent trait among distantly related clades in the Thamnophilidae that biased previous taxonomic and ecological work into recognizing Myrmotherula as a natural and taxonomic unit. Optimum body size values are associated with specific habitats and foraging forest strata that have likely contributed to a convergent evolution pattern among these clades. Shape variation in the complex is greater than previously acknowledged and is far from showing high levels of phenotypic similarity. For some specific traits, such as tail, tarsus, and hallux, it is likely that selective pressures have contributed to distinct morphologies suitable for different environmental conditions, therefore enabling co-existence and high levels of syntopy at local spatial scales (Gómez et al. 2010). Further, quantitative data on habitat use and foraging behavior (sensu Remsen and Robinson 1990; Stotz 1990) will allow a clearer understanding of the adaptive basis of ecomorphological traits.

\section{ACKNOWLEDGMENTS}

We are grateful to curators and collection managers of the American Museum of Natural History (AMNH), Field Museum of Natural History (FMNH), Instituto Alexander von Humboldt (IAvH), Instituto de Ciencias Naturales (ICN), Instituto Nacional de Pesquisas da Amazônia (INPA), University of Kansas Natural History Museum (KU), Laboratório de Genética e Evolução Molecular de Aves Universidade de São Paulo (LGEMA), Coleção de Ornitologia do Museu de Ciências e Tecnologia da Pontifícia Universidade Católica do Rio Grande do Sul (MCP), Museu Paraense Emílio Goeldi (MPEG), Museu de Zoologia Universidade de São Paulo (MZUSP), United States National Museum of Natural History (USNM), and University of Washington Burke Museum (UWBM). R. Belmonte-Lopes, M. Bornschein, and A. M. Cuervo provided access to sequences from some samples housed at MCP and IAvH. N. Aristizábal assisted in obtaining sequences. S. Claramunt shared his expertise on how to gather and analyze morphometric data. B. M. Whitney provided valuable information on the ecology of study species. We thank J. A. Chaves for his assistance designing and executing the antwren illustrations. GAB is grateful to instructors at the National Science Foundation (NSF) R Macroevolution Workshop 2011. This research was supported by grants from the Frank Chapman Memorial Fund-AMNH, the American Ornithologists' Union, the LSUMNS Big Day Fund, and LSU Biograds to GAB, NSF grants DEB-0841729 and DBI-0400797 to RTB, and DEB1011435 to GAB. B. C. Carstens, K. E. Harms, P. C. Stouffer, and A. M. Grooters, as members of GAB's doctoral committee, provided useful guidance during the development of this project. L. J. Harmon, S. Claramunt, F. Burbrink, and two anonymous reviewers provided valuable comments to this manuscript. The authors declare no conflict of interest.

\section{DATA ARCHIVING}

The doi for our data is $10.5061 /$ dryad.21sf7.

\section{LITERATURE CITED}

Akaike H. 1974. A new look at the statistical model identification. IEEE Trans. Autom. Contr. 19:716-723.

Aliabadian M., M. Kaboli, M. I. Förschler, V. Nijman, A. Chamani, A. Tillier, R. Prodon, E. Pasquet, P. G. P. Ericson, and D. Zuccon. 2012. Convergent evolution of morphological and ecological traits in the open-habitat chat complex (Aves, Muscicapidae: Saxicolinae). Mol. Phyl. Evol. 65:3545 .

Anderson, D. R. 2008. Model based inference in the life sciences: a primer on evidence. Springer, New York, NY.

Baldwin, S. P., H. C. Oberholser, and L. G. Worley. 1931. Measurements of birds. Scientific Publication Cleveland Museum of Natural History II, Cleveland, $\mathrm{OH}$.

Barker, F. K., Barrowclough, G. F., and Groth, J. G. 2002. A phylogenetic hypothesis for passerine birds: taxonomic and biogeographic implications of an analysis of nuclear DNA sequence data. Proc. R. Soc. B 269:295-308.

Bell, G. 2010. Fluctuating selection: the perpetual renewal of adaptation in variable environments. Philos. Trans. R. Soc. B 365:87-97.

Belmonte-Lopes, R., G. A. Bravo, M. R. Bornschein, G. Maurício, M. R. Pie, and R. T. Brumfield. 2012. Genetic and morphological data support placement of Myrmotherula gularis Spix) in the monotypic genus Rhopias Cabanis and Heine (Aves: Passeriformes: Thamnophilidae). Zootaxa 3451:1-16.

Blackledge, T. A., and R. G. Gillespie. 2004. Convergent evolution of behavior in an adaptive radiation of Hawaiian web-building spiders. Proc. Natl Acad. Sci. USA. 101:16228-16233. 
Bravo, G. A., R. T. Chesser, and R. T. Brumfield. 2012a. Isleria, a new genus of antwren (Aves: Passeriformes: Thamnophilidae). Zootaxa 3195:6167.

Bravo, G. A., J. V. Remsen Jr., B. M. Whitney, and R. T. Brumfield. 2012b. DNA sequence data reveal a subfamily-level divergence within Thamnophilidae (Aves: Passeriformes). Mol. Phylogenet. Evol. 65:287293.

Brumfield, R. T., and S. V. Edwards. 2007. Evolution into and out of the Andes: a Bayesian analysis of historical diversification in Thamnophilus antshrikes. Evolution 61:346-367.

Brumfield, R. T., J. G. Tello, Z. A. Cheviron, M. D. Carling, N. Crochet, and K. V. Rosenberg. 2007. Phylogenetic conservatism and antiquity of a tropical specialization: army-ant-following in the typical antbirds (Thamnophilidae). Mol. Phylogenet. Evol. 45:113.

Butler, M., and A. King. 2004. Phylogenetic comparative analysis: a modeling approach for adaptive evolution. Am. Nat. 164:683-695.

Claramunt, S. 2010. Discovering exceptional diversifications at continental scales: the case of the endemic families of Neotropical suboscine passerines. Evolution 64:2004-2019.

Claramunt, S., E. P. Derryberry, J. V. Remsen Jr., and R. T. Brumfield. 2012. Ecological opportunity and diversification in a continental radiation of birds: climbing adaptations and cladogenesis in the Furnariidae. Am. Nat. 179:649-666.

Conway-Morris S. 2009. Evolution and convergence: some wider considerations. Pp. 46-67 in S. C. Morris, ed. The deep structure of biology: is convergence sufficiently ubiquitous to give a directional signal? Templeton Foundation Press, West Conshohocken, PA.

Cooper, N., W. Jetz, and R. P. Freckleton. 2010. Phylogenetic comparative approaches for studying niche conservatism. J. Evol. Biol. 23:25292539.

Corbin, C. E. 2008. Foraging ecomorphology within North American flycatchers and a test of concordance with southern African species. J. Ornithol. 148:83-95.

Crisp, M. D., and L. G. Cook. 2012. Phylogenetic niche conservatism: what are the underlying evolutionary and ecological causes? New Phytol. 196:681-694.

Darroch, J. N., and J. E. Mosimann. 1985. Canonical and principal components of shape. Biometrika 72:241-252.

Derryberry, E. P., S. Claramunt, G. Derryberry, R. T. Chesser, J. Cracraft, A. Aleixo, J. Pérez-Emán, J. V. Remsen Jr., and R. T. Brumfield. 2011. Lineage diversification and morphological evolution in a large-scale continental radiation: the Neotropical ovenbirds and woodcreepers (Aves: Furnariidae). Evolution 65:2973-2986.

Develey, P. F., and C. A. Peres. 2000. Resource seasonality and the structure of mixed species bird flocks in a coastal Atlantic forest of southeastern Brazil. J. Trop. Ecol. 16:33-53.

Develey, P. F., and P. C. Stouffer. 2001. Effects of roads on movements by understory birds in mixed-species flocks in Central Amazonian Brazil. Conserv. Biol. 15:1416-1422.

Drummond, A. J., and A. Rambaut. 2007. BEAST: Bayesian evolutionary analysis by sampling trees. BMC Evol. Biol. 7:214. doi:10.1186/14712148-7-214.

Drummond, A. J., S. Y. W. Ho, M. J. Phillips, and A. Rambaut. 2006. Relaxed phylogenetics and dating with confidence. PLoS Biol. 4:e88.

Drummond A. J., B. Ashton, S. Buxton, M. Cheung, A. Cooper, C. Duran, M. Field, J. Heled, M. Kearse, S. Markowitz, et al. 2011. Geneious v5.4. Available at http://www.geneious.com. Accessed July 25, 2011.

Edwards, S., B. Vanhooydonck, A. Herrel, G. J. Measey, and K. A. Tolley. 2012. Convergent evolution associated with habitat decouples phenotype from phylogeny in a clade of lizards. PLoS One 7:e51636.
Estes, S., and S. J. Arnold. 2007. Resolving the paradox of stasis: models with stabilizing selection explain evolutionary divergence on all timescales. Am. Nat. 169:227-244.

Felsenstein, J. 1985. Phylogenies and the comparative method. Am. Nat. 125:1-15.

- 1988. Phylogenies and quantitative characters. Ann. Rev. Ecol. Syst. 19:445-471.

Fitzpatrick, J. W. 1985. Form, foraging behavior, and adaptive radiation in the Tyrannidae. Ornithol. Monogr. 36:447-4470.

Gómez, J. P., G. A. Bravo, R. T. Brumfield, J. G. Tello, and C. D. Cadena. 2010. A phylogenetic approach to disentangling the role of competition and habitat filtering in community assembly of Neotropical forest birds. J. Anim. Ecol. 79:1181-1192.

Gould, S. J., and E. S. Vrba. 1982. Exaptation-a missing term in the science of form. Paleobiology 8:4-15.

Gradwohl, J., and R. Greenberg. 1980. The formation of antwren flocks on Barro Colorado Island, Panamá. Auk 97:385-395.

Grant, P. R., and B. R. Grant. 2002. Unpredictable evolution in a 30-year study of Darwin's finches. Science 296:707-711.

Grant, P. R., B. R. Grant, J. A. Markert, L. F. Keller, and K. Petren. 2004. Convergent evolution of Darwin's finches caused by introgressive hybridization and selection. Evolution 58:1588-1599.

Greenberg, R. 1979. Body size, breeding habitat, and winter exploitation systems in Dendroica. Auk 96:756-766.

- 1981. Dissimilar bill shapes in New World versus temperate forage foliage-gleaning birds. Oecologia 49:143-147.

Greve, M., K. J. Gaston, B. J. van Rensburg, and S. L. Chown. 2008. Environmental factors, regional body size distributions and spatial variation in body size of local avian assemblages. Global Ecol. Biogeogr. 17:514523.

Groth, J. G., and G. F. Barrowclough. 1999. Basal divergences in birds and the phylogenetic utility of the nuclear RAG-1 gene. Mol. Phylo. Evol. 12:115-123.

Hackett, S., and K. V. Rosenberg. 1990. Comparison of phenotypic and genetic differentiation in South American antwrens (Formicariidae). Auk 107:473-489.

Hamilton, T. H. 1958. Adaptive variation in the genus Vireo. Wilson Bull. 70:307-346.

Hansen, T. F. 1997. Stabilizing selection and the comparative analysis of adaptation. Evolution 51:1341-1351.

Harmon, L. J., J. A. Schulte, A, Larson, and J. B. Losos. 2003. Tempo and mode of evolutionary radiation in iguanian lizards. Science 301:961964.

Harmon, L. J., J. Kolbe, J. Cheverud, and J. B. Losos. 2005. Convergence and the multidimensional niche. Evolution 59:409421.

Harmon L. J., J. T. Weir, C. D. Brock, R. E. Glor, and W. Challenger. 2008. GEIGER: investigating evolutionary radiations. Bioinformatics 24:129_ 131.

Harmon, L. J., J. B. Losos, T. J. Davies, R. G. Gillespie, J. L. Gittleman, W. B. Jennings, K. H. Kozak, M. A. McPeek, F. Moreno-Roark, T. J. Near, et al. 2010. Early bursts of body size and shape evolution are rare in comparative data. Evolution 64:2385-2396.

Huelsenbeck, J. P., and F. Ronquist. 2001. MRBAYES: Bayesian inference of phylogenetic trees. Bioinformatics 17:754-755.

Hulsey, C. D., R. J. Roberts, A. S. P. Lin, R. Guldberg, and J. T. Streelman. 2008. Convergence in a mechanically complex phenotype: detecting structural adaptations for crushing in cichlid fish. Evolution 62:15871599.

Hunt, G. 2006. Fitting and comparing models of phyletic evolution: random walks and beyond. Paleobiology 32:578-601. 
Ingram, T., and L. Mahler. 2013. SURFACE: detecting convergent evolution from comparative data by fitting Ornstein-Uhlenbeck models with stepwise Akaike Information Criterion. Methods Ecol. Evol. 4:416-425.

Irestedt, M., J. Fjeldså, J. A. Nylander, and P. G. P. Ericson. 2004. Phylogenetic relationships of typical antbirds (Thamnophilidae) and test of incongruence based on Bayes factors. BMC Evol. Biol. 4:23.

Irschick, D. J., J. J. Meyers, Husak, J. F., and J. F. Le Galliard. 2008. How does selection operate on whole-organism functional performance capacities? A review and synthesis. Evol. Ecol. Res. 10:177-196.

Isler, M. L., D. R. Lacerda, P. R. Isler, S. J. Hackett, K. V. Rosenberg, and R. T. Brumfield. 2006. Epinecrophylla, a new genus of antwrens (Aves: Passeriformes: Thamnophilidae). P. Biol. Soc. Wash. 119:522-527.

Katoh, K., K. Misawa, K. I. Kuma, and T. Miyata. 2002. MAFFT: a novel method for rapid multiple sequence alignment based on fast Fourier transform. Nucleic Acids Res. 30:3059-3066.

Kolbe, J. J., L. J. Revell, B. Szekely, E. D. Brodie III, and J. B. Losos. 2011 Convergent evolution of phenotypic integration and its alignment with morphological diversification in Caribbean Anolis ecomorphs. Evolution 65:3608-3624

Kozak, K. H., A. Larson, R. M. Bonett, and L. J. Harmon. 2005. Phylogenetic analysis of ecomorphological divergence, community structure, and diversification rates in dusky salamanders (Plethodontidae: Desmognathus). Evolution 59:2000-2016.

Kozak, K. H., R. W. Mendyk, and J. J. Wiens. 2009. Can parallel diversification occur in sympatry? repeated patterns of body-size evolution in coexisting clades of North American salamanders. Evolution 63:17691784.

Kumar, S., Å. Skjæveland, R. J. S. Orr, P. Enger, T. Ruden, B.-H. Mevik, F. Burki, A. Botnen, and K. Shalchian-Tabrizi. 2009. AIR: a batchoriented web program package for construction of supermatrices ready for phylogenomic analyses. BMC Bioinform. 10:357.

Labra, A., J. Pienaar, and T. Hansen. 2009. Evolution of thermal physiology in Liolaemus lizards: adaptation, phylogenetic inertia, and niche tracking. Am. Nat. 174:204-220.

Larson, A., and J. B. Losos. 2004. Phylogenetic systematics of adaptation. Pp. 187-220 in M. R. Rose and G. V. Lauder, eds. Adaptation. Academic Press, San Diego, CA.

Li, C., G. Lu, and G. Orti. 2008. Optimal data partitioning and a test case for ray-finned fishes (Actinopterygii) based on ten nuclear loci. Syst. Biol. 57:519-539.

Lindgren, A. R., M. S. Pankey, F. G. Hochberg, and T. H. Oakley. 2012. A multi-gene phylogeny of Cephalopoda supports convergent morphological evolution in association with multiple habitat shifts in the marine environment. BMC Evol. Biol. 12:129.

Losos, J. B. 1990. Ecomorphology, performance capability, and scaling of West Indian Anolis lizards: an evolutionary analysis. Ecol. Monogr. 60:369-388.

- 2008. Phylogenetic niche conservatism, phylogenetic signal and the relationship between phylogenetic relatedness and ecological similarity among species. Ecol. Lett. 11:995-1003.

. 2011. Convergence, adaptation, and constraint. Evolution 65:18271840.

MacArthur, R., and R. Levins 1967. The limiting similarity, convergence, and divergence of coexisting species. Am. Nat. 101:377-385.

Mahler, D. L., L. J. Revell, R. E. Glor, and J. B. Losos. 2010. Ecological opportunity and the rate of morphological evolution in the diversification of Greater Antillean anoles. Evolution 64:2731-2745.

Mahler, D. L., T. Ingram, and J. B. Losos. 2013. Exceptional convergence on the macroevolutionary landscape in island lizard radiations. Science 341:292-295.
McGee, M. D., and P. C. Wainwright. 2013. Convergent evolution as a generator of phenotypic diversity in threespine stickleback. Evolution 67:1204-1208.

Miles, D. B., and R. E. Ricklefs. 1984. The correlation between ecology and morphology in deciduous forest passerine birds. Ecology 65:1629-1640.

Miller, M. A., W. Pfeiffer, and T. Schwartz. 2010. Creating the CIPRES Science Gateway for inference of large phylogenetic trees. Pp. 1-8 in Proceedings of the Gateway Computer Environments workshop, 14-14 November, New Orleans, LA.

Mosimann, J. E. 1970. Size allometry: size and shape variables with characterizations of the lognormal and generalized gamma distributions. J. Am. Stat. Assoc. 65:930-945.

Mosimann, J. E., and F. C. James. 1979. New statistical methods for allometry with application to Florida Red-winged Blackbirds. Evolution 33:444 459.

Moyle, R., R. T. Chesser, R. T. Brumfield, J. G. Tello, D. Marchese, and J. Cracraft. 2009. Phylogeny and phylogenetic classification of the antbirds, ovenbirds, woodcreepers, and allies (Aves: Passeriformes: infraorder Furnariides). Cladistics 25:386-405.

Munn, C. A. 1985. Permanent canopy and understory flocks in Amazonia: species composition and population density. Ornithol. Monogr. 36:683712.

Munn, C. A., and J. W. Terborgh. 1979. Multi-species territoriality in Neotropical foraging flocks. Condor 81:338-347.

Murphy, E. C. 1985. Bergmann's rule, seasonality, and geographic variation in body size of House Sparrows. Evolution 39:1327-1334.

Muschick, M., A. Indemaur, and W. Salzburger. 2012. Convergent evolution within an adaptive radiation of cichlids fishes. Curr. Biol. 22:2362-2368.

Norberg, U. M. 1979. Morphology of the wings, legs and tail of three coniferous forest tits, the Goldcrest, and the Treecreeper in relation to locomotor pattern and feeding station selection. Phil. Trans. R. Soc. Lond. B 287:131-165.

Nyakatura, J. A. 2012. The convergent evolution of suspensory posture and locomotion in tree sloths. J. Mammal. Evol. 19:225-234.

Nylander, J. A. A. 2004. MrModeltest2. v2.3. Evolutionary Biology Center, Uppsala University. Uppsala, Sweden. Available at http://www.abc. se/rnylander/. Accessed January 31, 2011.

Ohlson J. I., M. Irestedt, P. G. P. Ericson, and J. Fjeldså. 2013. Phylogeny and classification of the New World suboscines (Aves, Passeriformes). Zootaxa 3613:1-35

Olson, V. A., R. G. Davies, C. D. L. Orme, G. H. Thomas, S. Meiri, T. M. Blackburn, K. J. Gaston, I. P. F. Owens, and P. M. Bennett. 2009. Global biogeography and ecology of body size in birds. Ecol. Lett. 12:249-259.

Oniki, Y. 1971. Wandering interspecific flocks in relation to ant-following birds at Belem, Brazil. Condor 73:372-374.

Paradis, E., J. Claude, and K. Strimmer. 2004. APE: analyses of phylogenetics and evolution in R language. Bioinformatics 20:289-290.

Pearson, D. L. 1971. Vertical stratification of birds in a tropical dry forest. Condor 73:46-55.

- 1977. Ecological relationships of small antbirds in Amazonian bird communities. Auk 94:292.

Poe, S., J. R. Goheen, and E. P. Hulebak. 2007. Convergent exaptation in solitary island lizards. Proc. R. Soc. B 274:2231-2237.

Powell, G. V. N. 1979. Structure and dynamics of interspecific flocks in a Neotropical mid-elevation forest. Auk 96:375-390.

Price, T. 1991. Morphology and ecology of breeding warblers along an altitudinal gradient in Kashmir, India. J. Anim. Ecol. 60:643-664.

R Development Core Team. 2011. R: a language and environment for statistical computing. R Foundation for Statistical Computing, Vienna, Austria Available at http://www.r-project.org. 
Remsen, J. V. Jr. 2003. The "Coerebidae": a polyphyletic taxon that dramatizes historical over-emphasis on bill shape as a taxonomic character. J. Avian Biol. 34:321-323.

Remsen, J. V. Jr., and S. K. Robinson. 1990. A classification scheme for foraging behavior of birds in terrestrial habitats. Stud. Avian Biol. 13:144 160.

Remsen, J. V. Jr., C. D. Cadena, A. Jaramillo, M. Nores, J. F. Pacheco, J. Perez-Eman, M. B. Robbins, F. G. Stiles, D. F. Stotz, and K. J. Zimmer. 2013. A classification of the bird species of South America. American Ornithologists' Union. [Online.] Available at: http://www.museum. 1su.edu/ $\backsim$ Remsen/SACCBaseline.html. Accessed September 13, 2013.

Revell, L. J. 2009. Size-correction and principal components for interspecific comparative studies. Evolution 63:3258-3268.

- 2012. Phytools: an R package for phylogenetic comparative biology (and other things). Methods Ecol. Evol. 3:217-223.

Revell, L. J., and D. C. Collar. 2009. Phylogenetic analysis of the evolutionary correlation using likelihood. Evolution 63:1090-1100.

Revell, L. J., L. J. Harmon, R. B. Langerhans, and J. J. Kolbe. 2007a. A phylogenetic approach to determining the importance of constraint on phenotypic evolution on the Neotropical lizard Anolis cristatellus. Evol. Ecol. Res. 9:261-282.

Revell, L. J., M. A. Johnson, J. A. Schulte, J. J. Kolbe, and J. B. Losos. 2007b. A phylogenetic test for adaptive convergence in rock-dwelling lizards. Evolution 61:2898-2912.

Revell, L. J., L. J. Harmon, and D. C. Collar. 2008. Phylogenetic signal, evolutionary process, and rate. Syst. Biol. 57:591-601.

Ricklefs, R. E., and J. Travis. 1980. A morphological approach to the study of avian community organization. Auk 97:321-338.

Ricklefs, R. E. 2006. Evolutionary diversification and the origin of diversityenvironment relationship. Ecology 87(Suppl.):S3-S13.

Ridgely, R. S., and G. Tudor. 1994. The birds of South America. The suboscine passerines. Vol. II. Univ. of Texas Press, Austin, TX.

Rosenberg, K. V. 1990. Dead-leaf foraging specialization in tropical forest birds: measuring resource availability and use. Stud. Avian Biol. 13:360368 .

- 1993. Diet selection in Amazonian antwrens: consequences of substrate specialization. Auk 110:361-375.

Rüber, L., and D. C. Adams. 2001. Evolutionary convergence of body shape and trophic morphology in cichlids from Lake Tanganyika. J. Evol. Biol. 14:325-332.

Scheffer, M., and E. H. van Nes. 2006. Self-organized similarity, the evolutionary emergence of groups of similar species. Proc. Natl. Acad. Sci. USA 103:6230-6235.

Schlumpberger, B. O., and S. S. Renner. 2012. Molecular phylogenetics of Echinopsis (Cactaeae): polyphyly at all levels and convergent evolution of pollination modes and growth forms. Am. J. Bot. 99:1335-1349.

Schulenberg, T. S. 1983. Foraging behavior, eco-morphology, and systematics of some antshrikes (Formicariidae: Thamnomanes). Wilson Bull. 95:505-521.

Sidlauskas, B. 2008. Continuous and arrested morphological diversification in sister clades of characiform fishes: a phylomorphospace approach. Evolution 62:3135-3156.

Simpson, G. G. 1944. Tempo and mode in evolution. Colombia Univ. Press, New York, NY.

Stamatakis, A. 2006. RAxML-VI-HPC: maximum likelihood-based phylogenetic analyses with thousands of taxa and mixed models. Bioinformatics 22:2688-2690.

Stayton, C. T. 2006. Testing hypotheses of convergence with multivariate data: morphological and functional convergence among herbivorous lizards. Evolution 60:824-841.
2008. Is convergence surprising? An examination of the frequency of convergence in simulated datasets. J. Theor. Biol. 252:1-14. doi:10.1016/j.jtbi.2008.01.008.

Stotz, D. F. 1990. Foraging and morphology in the avian genus Myrmotherula. Ph.D. diss., University of Chicago, Chicago, IL.

Stotz, D. F, J. W. Fitzpatrick, T. A. Parker III, and D. K. Moskovitz. 1996. Neotropical birds: ecology and conservation. Univ. of Chicago Press, Chicago, IL and London.

Swofford, D. L. 2003. PAUP*. Phylogenetic analysis using parsimony (*and other methods). v4. Sinauer Associates, Sunderland, MA. Available at http://paup.csit.fsu.edu/. Accessed June 10, 2010.

Tello, J. G., R. G. Moyle, D. Marchese, and J. Cracraft. 2009. Phylogeny and phylogenetic classification of the tyrant flycatchers, cotingas, manakins, and their allies (Aves: Tyrannides). Cladistics 25:429467.

Thiollay, J. M. 2003. Comparative foraging behavior between solitary and flocking insectivores in a Neotropical forest: does vulnerability matter? Ornitol. Neotrop. 14:47-65.

Thomas, A. L. R., and A. Balmford. 1995. How natural selection shapes birds' tails. Am. Nat. 146:848-868.

Uyeda, J. C., T. Hansen, S. J. Arnold, and J. Pienaar. 2011. The millionyear wait for macroevolutionary bursts. Proc. Natl. Acad. Sci. USA 108:15908-15913.

Whitney, B. M. 1994. Behavior, vocalizations, and possible relationships of four Myrmotherula antwrens (Formicariidae) from eastern Ecuador. Auk 111:469-475.

Whitney, B. M., and J. F. Pacheco. 1997. Behavior, vocalizations, and relationships of some Myrmotherula antwrens (Thamnophilidae) in eastern Brazil, with comments on the "plain-winged" group. Orn. Monogr. 48:809-819.

Wiens, J. J., and C. H. Graham. 2005. Niche conservatism: integrating evolution, ecology, and conservation biology. Ann. Rev. Ecol. Evol. Syst. 35:519-539.

Wiens, J. J., M. C. Brandley, and T. W. Reeder. 2006. Why does a trait evolve multiple times within a clade? Repeated evolution of snakelike body form in squamate reptiles. Evolution 60:123-141.

Wiens, J. J., D. D. Ackerly, A. P. Allen, B. L. Anacker, L. B. Buckley, H. V. Cornell, E. I. Damschen, T. J. Davies, J. A. Grytnes, S. P. Harrison, et al. 2010. Niche conservatism as an emerging principle in ecology and conservation biology. Ecol. Lett. 13:13101324.

Wiley, R. H. 1980. Multispecies antbird societies in lowland forests of Surinam and Ecuador: stable membership and foraging differences. J. Zool. 191:127-145.

Wilgenbusch, J. C., D. L. Warren, and D. L. Swofford. 2004. AWTY: a system for graphical exploration of MCMC convergence in Bayesian phylogenetic inference. Available at http://king2.scs. fsu.edu/CEBProjects/awtu/awtu-start.php. Accessed November 30, 2011.

Williams, E. E. 1972. The origin of faunas. Evolution of lizard congeners in a complex island fauna: a trial analysis. Evol. Biol. 6:4789.

Winkler, H., and M. Preleuthner. 2001. Behaviour and ecology of birds in tropical rain forest canopies. Plant Ecol. 153:193-202.

Zimmer, K. J., and M. L. Isler. 2003. Family Thamnophilidae (typical antbirds). Pp. 448-681 in J. Del Hoyo, A. Elliott, and D. Christie, eds. Handbook of birds of the world. Vol. 8, broadbills to tapaculos. Lynx Edicions, Barcelona.

Associate Editor: F. Burbrink 
GUSTAVO A. BRAVO ET AL.

\section{Supporting Information}

Additional Supporting Information may be found in the online version of this article at the publisher's website:

Table S1. Taxa and sequences used in this study with tissue collection voucher number.

Table S2. Partitioning strategies evaluated to construct the phylogenetic hypotheses of the Myrmotherula complex.

Table S3. Substitution model selected by mrmodeltest for each of the 16 partitions included in the most informative partition strategy.

Table S4. List of voucher study specimens examined and measured for ecomorphological analyses of the Myrmotherula complex.

Table S5. Foraging strata, habitat, and mixed-flocking behavior categorization of the species in the formicivorini.

Table S6. Information theoretic statistics and ranking for each of the three models of habitats, foraging strata, and mixed-flocking behavior change evaluated in the formicivorini clade.

Figure S1. Fifty percent majority-rule Bayesian topology of a subset of the Thamnophilidae showing phylogenetic relationships of the Myrmotherula complex.

Figure S2. Correlations between pPCs and log-transformed body weight.

Figure S3. Ancestral reconstruction of habitat (top left), foraging strata (top right), and mixed-species foraging behavior (bottom). 